Review

\title{
Structural Insights into Bacillus thuringiensis Cry, Cyt and Parasporin Toxins
}

Chengchen Xu ${ }^{1,2}$, Bi-Cheng Wang ${ }^{2}$, Ziniu Yu ${ }^{1, *}$ and Ming Sun ${ }^{1, *}$

1 State Key Laboratory of Agricultural Microbiology, College of Life Science and Technology, Huazhong Agricultural University, Wuhan 430070, China; E-Mail: chenchen.609609@gmail.com

2 Department of Biochemistry and Molecular Biology, University of Georgia, Athens, GA 30602, USA; E-Mail: wang@bcl1.bmb.uga.edu

* Authors to whom correspondence should be addressed;

E-Mails: yz41@mail.hzau.edu.cn (Z.Y.); m98sun@mail.hzau.edu.cn (M.S.);

Tel.: +86-27-8739-6030 (Z.Y.); +86-27-8728-3455 (M.S.);

Fax: +86-27-8728-7254 (Z.Y.); +86-27-8728-0670 (M.S.).

Received: 29 April 2014; in revised form: 26 August 2014 / Accepted: 28 August 2014 /

Published: 16 September 2014

\begin{abstract}
Since the first X-ray structure of Cry3Aa was revealed in 1991, numerous structures of $B$. thuringiensis toxins have been determined and published. In recent years, functional studies on the mode of action and resistance mechanism have been proposed, which notably promoted the developments of biological insecticides and insect-resistant transgenic crops. With the exploration of known pore-forming toxins (PFTs) structures, similarities between PFTs and B. thuringiensis toxins have provided great insights into receptor binding interactions and conformational changes from water-soluble to membrane pore-forming state of $B$. thuringiensis toxins. This review mainly focuses on the latest discoveries of the toxin working mechanism, with the emphasis on structural related progress. Based on the structural features, B. thuringiensis Cry, Cyt and parasporin toxins could be divided into three categories: three-domain type $\alpha$-PFTs, Cyt toxin type $\beta$-PFTs and aerolysin type $\beta$-PFTs. Structures from each group are elucidated and discussed in relation to the latest data, respectively.
\end{abstract}

Keywords: Bacillus thuringiensis; Cry toxin; Cyt toxin; parasporin; pore-forming toxins 


\section{Introduction}

Bacillus thuringiensis, as a Gram-positive soil bacterium, is a member of the $B$. cereus group that includes five other species: B. cereus, B. anthracis, B. mycoides, B. pseudomycoides, and $B$. weihenstephanensi. It produces parasporal crystal toxins of insecticidal properties during sporulation, which could be distinguished from other species [1]. With significant but specific toxicity, B. thuringiensis toxins have been demonstrated against many typical insect orders, such as Lepidoptera (butterflies and moths), Diptera (flies and mosquitoes) and Coleoptera (beetles and weevils). Newly emerging toxins have presented their toxicities towards other insect orders of Hymenoptera, Orthoptera, Hemiptera, Isoptera, Mallophaga, Thisanoptera, etc., and some pests, such as nematodes and mites [2]. These susceptible targets include major invertebrate plant pests from agricultural and forests, as well as some insect vectors of mammalian pathogens [3]. Today, a large number of B. thuringiensis strains have been isolated and classified into at least $71 \mathrm{H}$ serotypes by their flagellar immunological reactions [4,5]. Meanwhile, based on the homology of amino acid sequence, more than 300 holotypes of $B$. thuringiensis toxins have been distinguished and categorized into $73 \mathrm{cry}$ and $3 \mathrm{cyt}$ families [6,7].

During sporulation phase, B. thuringiensis produces two types of Crystal (Cry) and Cytolytic (Cyt) parasporal toxins: [2]. Cry toxin is specifically toxic to the majority of insect orders; some Cry toxins have an insecticidal spectrum spanning two or three orders [8,9]. Cry toxin is described as: a parasporal inclusion (Crystal) protein from B. thuringiensis that exhibits toxic effects to a target organism, or any protein that has obvious sequence similarity to a known Cry toxin [10]. Cyt toxin shows limited sequence homology to the Cry family. It is toxic to the dipteran larva in vivo, but exhibits a broad range of cytotoxicity against dipteran and mammalian cells in vitro [11]. Cyt toxin is taken as: a parasporal inclusion (Crystal) protein from B. thuringiensis that exhibits hemolytic activity, or any protein that has obvious sequence similarity to a known Cyt protein [10].

Parasporin, which was isolated from non-insecticidal inclusion proteins of B. thuringiensis, has been demonstrated with strong cytocidal activity against human cancer cells [12]. Although at first parasporin was distinguished as Cry category, its unexpected remarkable cytotoxicity and increasing members made it unique. In 2006, the Committee of Parasporin Classification and Nomenclature was organized and defined the term 'parasporin' as “B. thuringiensis and related bacterial parasporal proteins that are non-hemolytic but capable of preferentially killing cancer cells" [13].

In addition, similar to parasporin, binary-like (Bin-like) and mosquitocidal-like (Mtx-like) toxins are related to Bin and Mtx toxins from L. sphaericus [14]. Also, the vegetative insecticidal protein (Vip) expressed before the stage of sporulation, represents a novel group of insecticidal toxin [15].

When digested by susceptible insect larvae, B. thuringiensis protoxin would be solubilized in alkaline gut environment and proteolytically cleaved by gut proteases [16]. After binding to the specific receptors on the brush border membrane of the midgut epithelium, the activated toxin would lead to insect death and allow spores to germinate [2]. Over the past few years, considerable efforts have been directed towards binding to toxin receptors, toxin structures and the mechanism of pore formation. Two models have been proposed: the pore formation model and the signaling pathway model $[17,18]$. However, because of lacking adequate evidences, several fundamental gaps — specific receptor interactions and the structure of transmembrane pores-are still beyond our understanding. 
On the other hand, with the rapid growth of commercialized insecticides and transgenic crops, insect resistance has become the primary threat to the application of $B$. thuringiensis toxins. To overcome the resistance, several strategies have been provided, including modifying receptor binding sites at the corresponding binding region or alternating receptor binding affinities by swapping domains within certain Cry toxins [19]. Research on B. thuringiensis toxin structures has contributed to and will continue to focus on the understanding of working mechanism and the development of long-term application in pest management.

B. thuringiensis toxins and pore-forming toxins (PFTs) share many common structural and functional features. PFTs is a major category of membrane-damaging toxins, which also could penetrate target cell membrane in a water-soluble form and generate pores, eventually leading to cell death [20,21]. By their transmembrane structure, PFTs are classified as two main groups: $\alpha$-pore-forming toxins $(\alpha$-PFTs) and $\beta$-pore-forming toxins ( $\beta$-PFTs). The $\alpha$-PFTs are predicted to form pores as a bundle of $\alpha$-helices, which includes colicins, exotoxin A, diphtheria toxins and so on. The $\beta$-PFTs, including aerolysin, epsilon, cholesterol-dependent cytolysin, $\alpha$-hemolysin, etc., are predicted to form $\beta$-barrel transmembrane pores [22]. In this review, according to the similarities of known or predicted structures between B. thuringiensis toxins and PFTs, we describe Cry, Cyt and parasporin toxins as three categories based on structural features: three-domain type $\alpha$-PFTs, Cyt toxin type $\beta$-PFTs and aerolysin type $\beta$-PFTs. Structural features of these three categories, similarities to the PFTs and structure-related functional progress are elucidated in detail.

\section{Cry Toxins}

\subsection{Structure of Three-Domain Cry Toxins}

The development of techniques in molecular biology, X-ray crystallography and Nuclear Magnetic Resonance (NMR) has revolutionized the understanding of protein structure at atomic level and the elucidation of their functions. By X-ray crystallography, several B. thuringiensis Cry toxins have been reported (Table 1) [23-31].

These elucidated structures of Cry toxins exhibit various specific insecticidal toxicities against insect orders of Dipterta, Lepidoptera, Coleoptera, and nematode, which obviously are sharing similar three-domain architectures (Figure 1A). Domain I is an $\alpha$-helix bundle and shows structural similarity with the pore-forming domain of colicin. It is proposed to be the pore-forming determinant when penetrating the membrane. Domain II is a $\beta$-prism of three antiparallel $\beta$-sheets packing together; two of them are in a typical 'Greek-key' topology and composed of four $\beta$-strands. It is suggested to be related to receptor binding. Domain III has a "jelly-roll" topology with the strands forming into a $\beta$-sandwich and is considered to be related to receptor recognition and membrane insertion [32]. Domain II and domain III reside at the same side of domain I, stacking against each other along helix $\alpha 7[23]$. 
Table 1. List of $B$. thuringiensis three-domain Cry toxin structures solved by X-ray crystallography.

\begin{tabular}{|c|c|c|c|c|c|c|c|c|c|}
\hline Toxin & Target Insects & Expressing Strain & Activation & Resolution & PDB ID & Domain I & Domain II & Domain III & References \\
\hline CrylAa & Lepidoptera & Bt kurstaki HD-1 & $\begin{array}{l}\text { Trypsin } \\
65 \mathrm{kDa}\end{array}$ & $2.25 \AA$ & $1 \mathrm{CIY}$ & resi 33-253 & resi $265-461$ & $\begin{array}{c}\text { resi } 463-609 \text {, } \\
\text { resi } 254264\end{array}$ & {$[23]$} \\
\hline CrylAc* & Lepidoptera & Bt kurstaki HD73 & $\begin{array}{l}\text { Trypsin } \\
65 \mathrm{kDa}\end{array}$ & $2.35 \AA$ & $4 \mathrm{ARX}$ & resi $31-263$ & resi $255-462$ & resi 463-609 & {$[24]$} \\
\hline Cry2Aa & $\begin{array}{c}\text { Diptera } \\
\text { Lepidoptera }\end{array}$ & Bt kurstaki HD-1 & $\begin{array}{l}\text { Protoxin } \\
62 \mathrm{kDa}\end{array}$ & $2.2 \AA$ & $1 \mathrm{I} 5 \mathrm{P}$ & resi $1-272$ & resi $273-473$ & resi 474-633 & {$[25]$} \\
\hline Cry3Aa & Coleoptera & Bt tenebrionis 1911 & $\begin{array}{l}\text { Papain } \\
67 \mathrm{kDa}\end{array}$ & $2.5 \AA$ & 1DLC & resi $61-290$ & resi $291-500$ & resi 501-644 & {$[26]$} \\
\hline Cry3Bb & Coleoptera & E. coli EG7231 & $67.2 \mathrm{kDa}$ & $2.4 \AA$ & $1 \mathrm{JI} 6$ & resi 64-294 & resi $295-503$ & resi 504-652 & {$[27]$} \\
\hline Cry4Aa & Diptera & Bt israelensis & $\begin{array}{l}\text { Trypsin } \\
65 \mathrm{kDa}\end{array}$ & $2.8 \AA$ & $2 \mathrm{C} 9 \mathrm{~K}$ & resi $68-321$ & resi $322-524$ & resi 525-679 & {$[28]$} \\
\hline Cry4Ba & Diptera & Bt israelensis & $\begin{array}{l}\text { Chymotrypsin } \\
68 \mathrm{kDa}\end{array}$ & $1.75 \AA$ & 1W99 & resi 84-282 & resi 283-466 & resi 467-641 & [29] \\
\hline Cry8Ea * & Coleoptera & Bt185 & $\begin{array}{c}\text { Chymotrypsin } \\
66.2 \mathrm{kDa} \\
\end{array}$ & $2.2 \AA$ & 3EB7 & resi 64-290 & resi $291-500$ & resi $501-652$ & {$[30]$} \\
\hline Cry5B & Nematode & $\begin{array}{c}\text { Bt kurstaki HD-1(Native) } \\
\text { E.coli M15(Sel-Met) }\end{array}$ & $\begin{array}{c}\text { Elastase } \\
66.14 \mathrm{kDa}\end{array}$ & $2.3 \AA$ & $4 \mathrm{D} 8 \mathrm{M}$ & resi $112-328$ & resi $341-541$ & resi 541-698 & {$[31]$} \\
\hline
\end{tabular}

* Three domain regions are estimated according to PDB results. 
Figure 1. The pore formation model of three-domain Cry1A toxin in the midgut lipid rafts. (A) Ribbon diagram of Cry1Aa structure. Three domains are colored in pale green, lemon and bright orange, respectively; (B) Sequential steps of the pore formation model. 1. Solubilized Cry1A is digested by the protease in the alkaline insect midgut; 2. Cry1A binds to the abundant GPI-anchored APN and ALP receptors in the lipid rafts with low affinity. This binding promotes the localization and concentration of the activated toxins; 3. Binding to the cadherin receptor facilitates the proteolytic cleavage of the helix $\alpha 1$ at $\mathrm{N}$-terminal end; 4. and 5. N-terminal cleavage induces the formation of pre-pore oligomer and increases the oligomer binding affinity to GPI-anchored APN and ALP receptors; 6. Oligomer inserts into the membrane, leading to pore-formation and cell lysis.

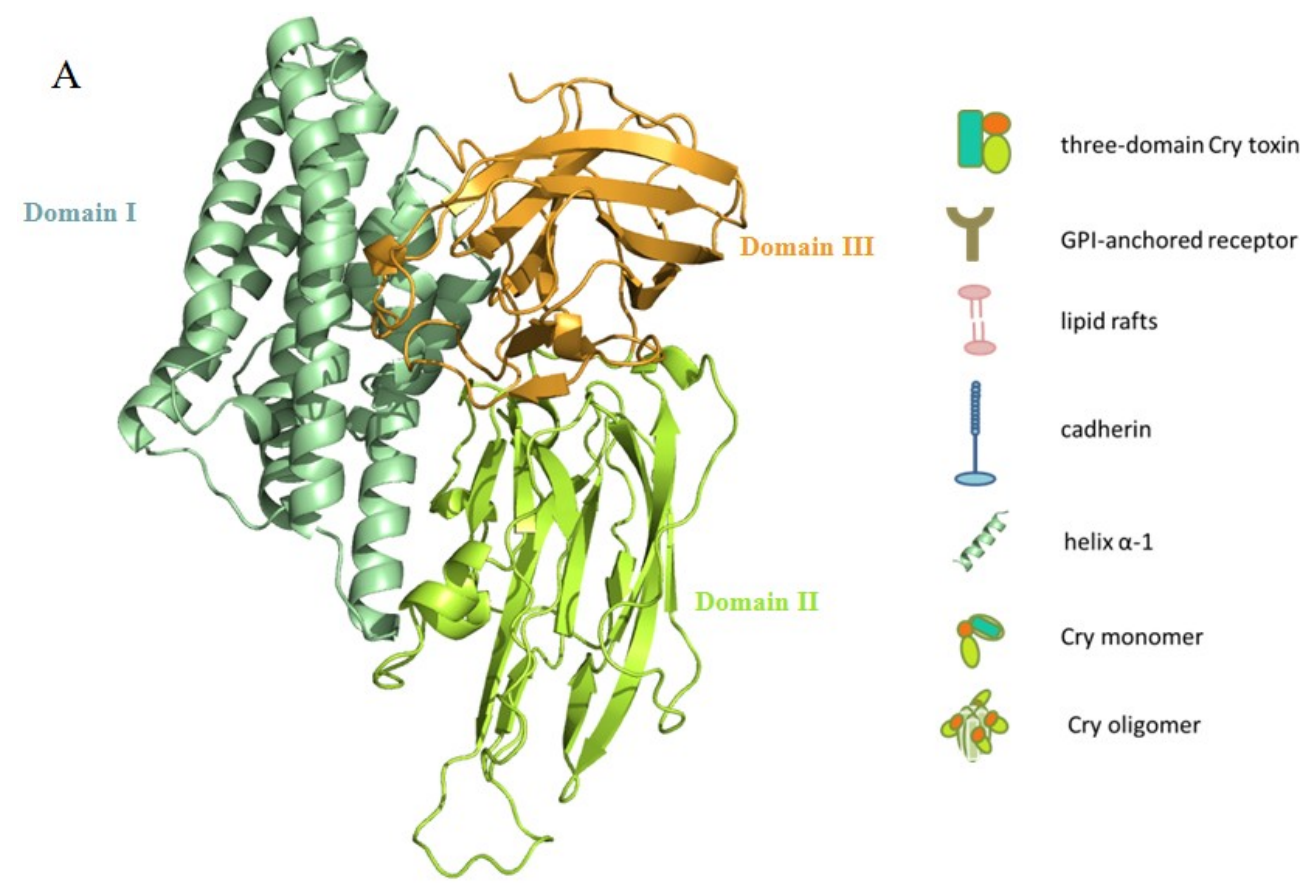

B

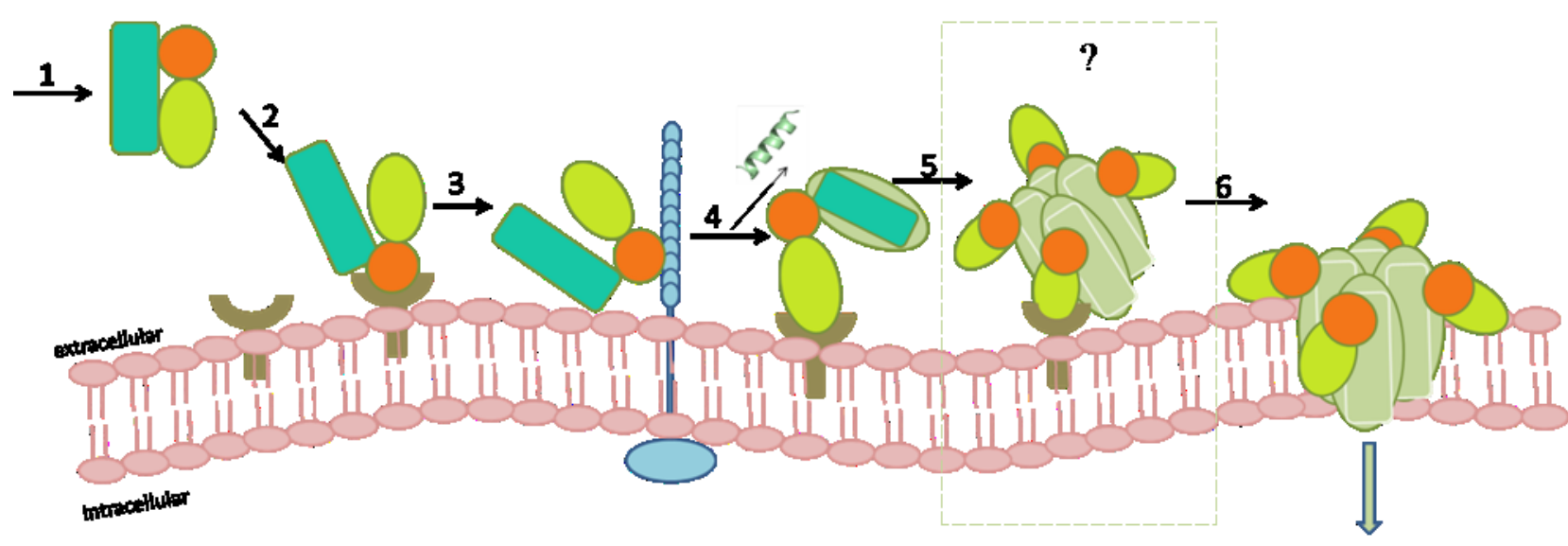


Complete amino acid sequence alignment of the three-domain Cry toxins reveals that most of the toxins contain five conserved blocks [2]. Conserved block 1 is in the central helix of domain I, block 2 at the domain I and domain II interface, block 3 at the boundary between domains II and domain III, block 4 in the central $\beta$-strand of domain III and block 5 at the end of domain III [32].

\subsubsection{Domain I of the Three-Domain Cry Toxins}

By structural alignment, domain I of Cry toxin shares a significant structural similarity with the pore-formation domain of $\alpha$-PFTs colicin A (Figure 2A). Therefore, it has been estimated that domain I might play an essential role in membrane penetration and pore formation after binding to the specific receptors [23]. In Cry3Aa, domain I consists of six amphipathic helices $(\alpha 1, \alpha 2, \alpha 3, \alpha 4, \alpha 6$ and $\alpha 7)$, which surround the hydrophobic central helix $\alpha 5$ [26]. Helix $\alpha 2$ is interrupted by a short loop section, consequently divided into helices $\alpha 2 \mathrm{a}$ and $\alpha 2 \mathrm{~b}$. In Cry1Aa, Cry2Aa, Cry4Aa, and Cry8Ea, helix $\alpha 2$ is also made up of two short $\alpha$-helices that are separated by a loop [23,25,30].

Figure 2. Structural comparison and sequence alignment of domain I of all structure solved three-domain Cry toxins and the pore-forming domain of colicin A (PDB ID 1COL). (A) Ribbon diagram of domain I of Cry4Aa (top) and the pore-forming domain of colicin A (bottom); (B) Multiple sequence alignment of Cry toxins and colicin A. Secondary structure elements $\alpha$-helices, $3_{10}$-helices and $\beta$-strands are denoted in blue as $\alpha, \eta$ and $\beta$, respectively. Figure was prepared by ESPript [33].

A
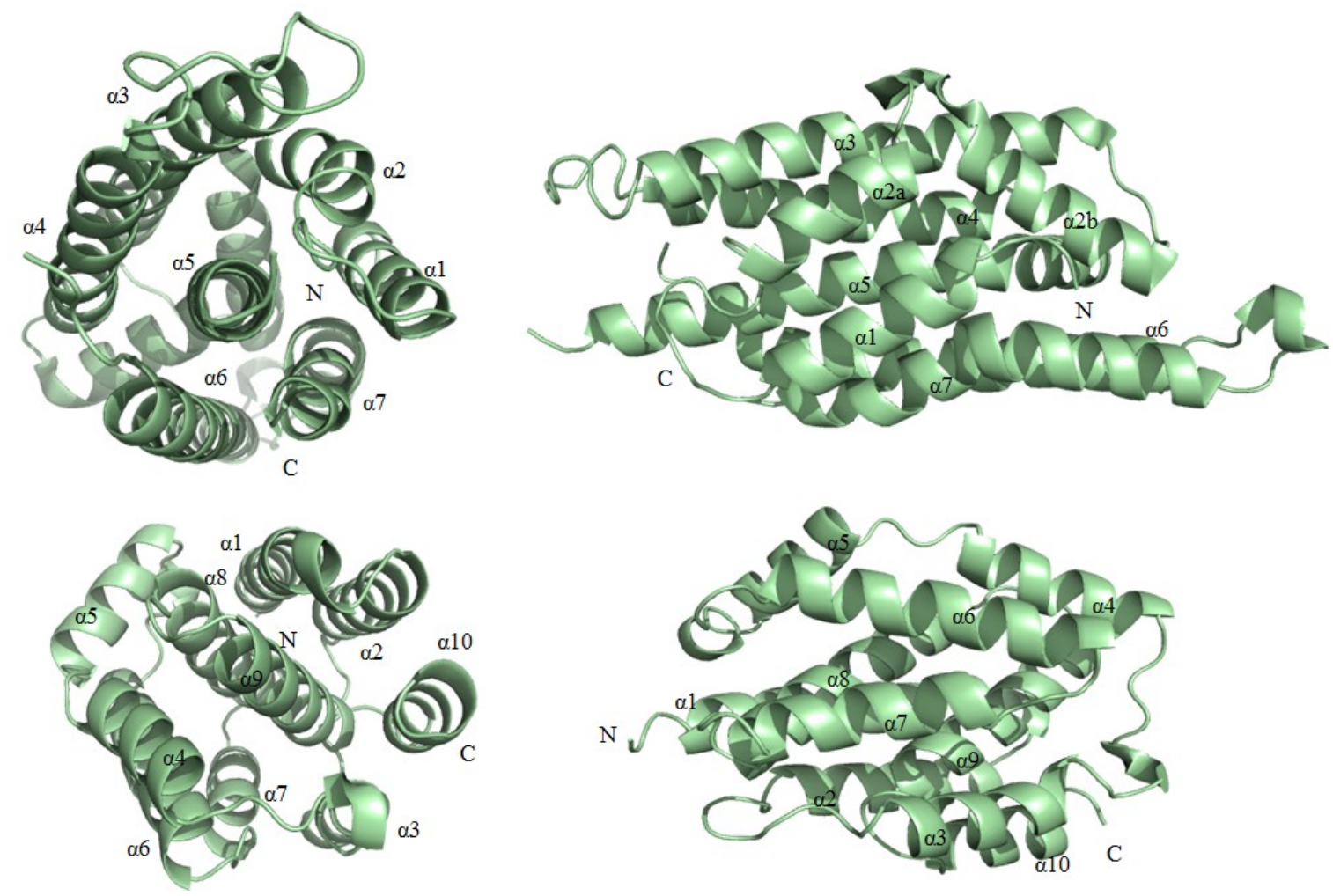
Figure 2. Cont.

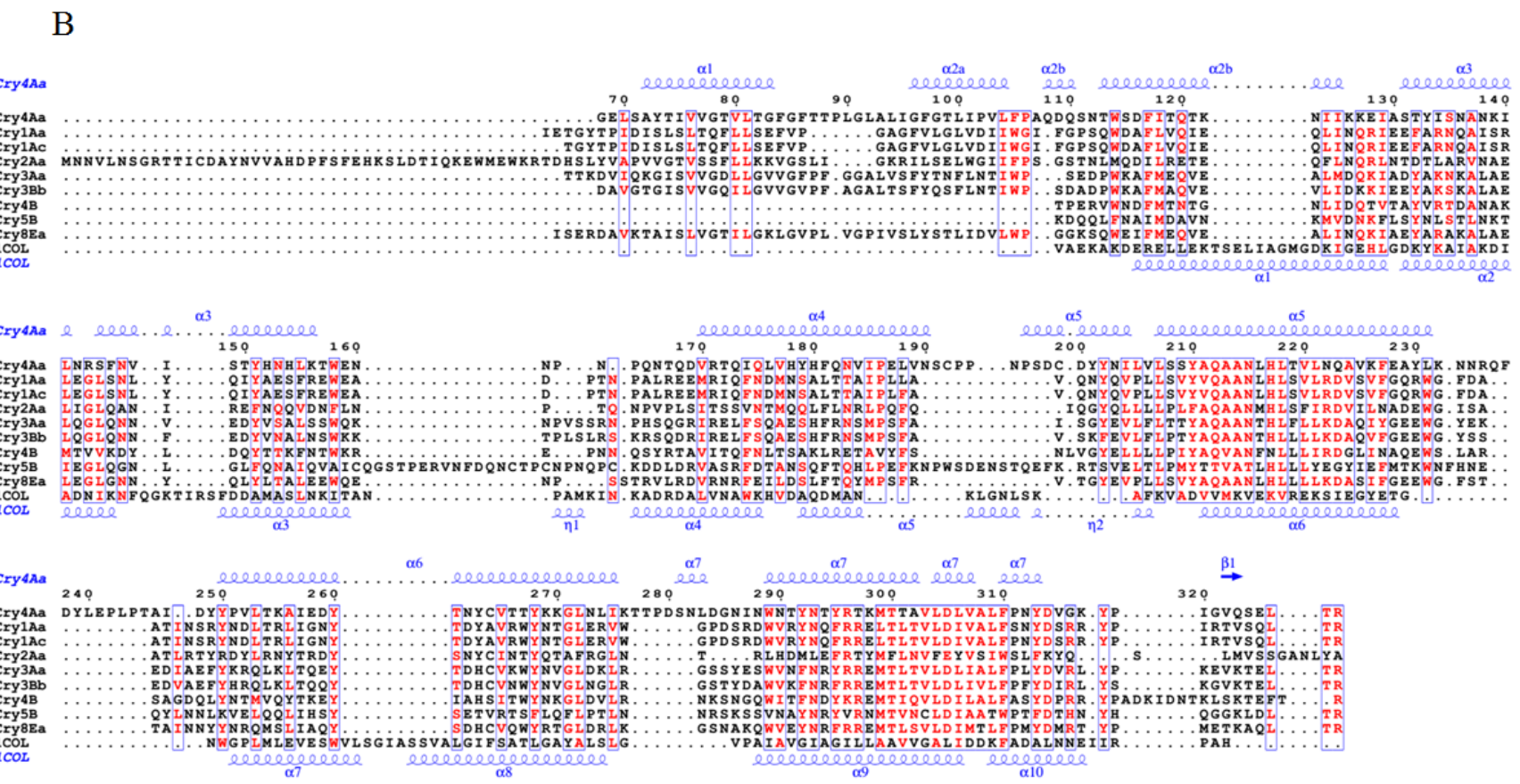

After proteolytic digestion, interactions between activated Cry toxins and receptors may facilitate the cleavage of helix $\alpha 1$, and then promote oligomerization. However, recent data have identified that without cadherin receptor, two helix $\alpha 1$ deleted Cry1AbMod and Cry1AcMod mutants could form oligomers by themselves and still remained toxic towards cadherin-silenced $M$. sexta and Bt-resistant P. gossypiella [34]. Moreover, the transgenic Cry1AbMod mutant was also toxic to the cadherin-silenced susceptible or tolerant M. sexta larvae [35]. Evidence from these examples provides not only a different point of view about the relationship of $\mathrm{N}$-terminal cleavage and oligomerization, but also a potential strategy to counter $B$. thuringiensis resistance in transgenic crops.

As the conserved block 1 covers the central helix $\alpha 5$ and block 2 is corresponding to the C-terminal helix $\alpha 7$, these regions together with their surrounding areas may play a role in its action [26]. Mutations in the helix $\alpha 4$ of Cry1Aa, Cry1Ac and Cry1Ab5 toxins decreased the pore-forming ability, providing the evidence that helix $\alpha 4$ may be involved in pore formation [36,37]. In Cry4Ba, site-directed mutations of two polar amino acids (Asn166 and Try170) at loop $\alpha 4-\alpha 5$ almost completely depleted the activity against $A$. aegypti larvae [38]. Similar evidence can also be found at residue Tyr202 of Cry4Aa within the same region [39]. Based on the features of domain I, an umbrella-like model was put forward. In this model, the hydrophobic helices $\alpha 4$ and $\alpha 5$ penetrates the bilayer as an antiparallel hairpin, while the remaining helices spread on the membrane out-surface with a conformation change [40]. The umbrella-like model exhibits the importance of hairpin $\alpha 4-\alpha 5$ as the hydrophobic core of domain I and displays an affinitive interaction of membrane penetration and pore formation in the lipid bilayer.

In the umbrella-like model, helix $\alpha 7$ shows a "semi-inserted" orientation and interacts with other helices, which may act as the binding sensor [40,41]. Site-mutagenesis within block 2 of Cry3A has suggested that helix $\alpha 7$ might also be necessary for structure stability [42]. In Cry4Ba, mutations at aromatic resides Trp243, Tyr249 and Phe246 within helix $\alpha 7$ displayed an obvious decrease in 
toxicities, while Y249 and F264L mutants stay structurally stable upon trypsin activation [43]. Although the hydrophobic core of $\alpha 4-\alpha 5$ helical hairpin is the key component of pore-formation, the working mechanism of domain I would be contributed by the collaborations of all the helices.

\subsubsection{Domain II of Three-Domain Cry Toxins}

Domain II is a $\beta$-prism of three antiparallel $\beta$-sheets and two short helices, with a hydrophobic core buried inside (Figure 3A). In Cry4Ba, sheet 1 composed of strands $\beta 5, \beta 2, \beta 3$, and $\beta 4$ and sheet 2 consisting of strands $\beta 8, \beta 7, \beta 6$, and $\beta 9$, are both in a 'Greek-key' motif. The third three-stranded sheet is formed by two separate fragments: $\mathrm{C}$-terminal stands $\beta 10$ and $\beta 11$; N-terminal strand $\beta 1$ and helix $\alpha 8$ [29]. By sequence homology, domain II shows the largest divergence, while domain III presents the highest similarity [29]. As the central part of the $\beta$-stands superimposes well, the primary difference is mainly found at the connecting loops.

Figure 3. Structural comparison and sequence alignment between domain II of three-domain Cry toxins and ZG16p protein (PDB ID 3APA). (A) Ribbon diagram of domain II of Cry4Aa (left) and ZG16p (right); (B) multiple sequence alignment of Cry toxins and ZG16p protein. Secondary structure elements $\alpha$-helices, $33_{10}$-helices and $\beta$-strands are denoted in blue and present as $\alpha, \eta$ and $\beta$, respectively. In ZG16p protein, putative sugar-binding involved GG loop, recognition loop, and binding loop are marked in orange, green, and purple, respectively.

A
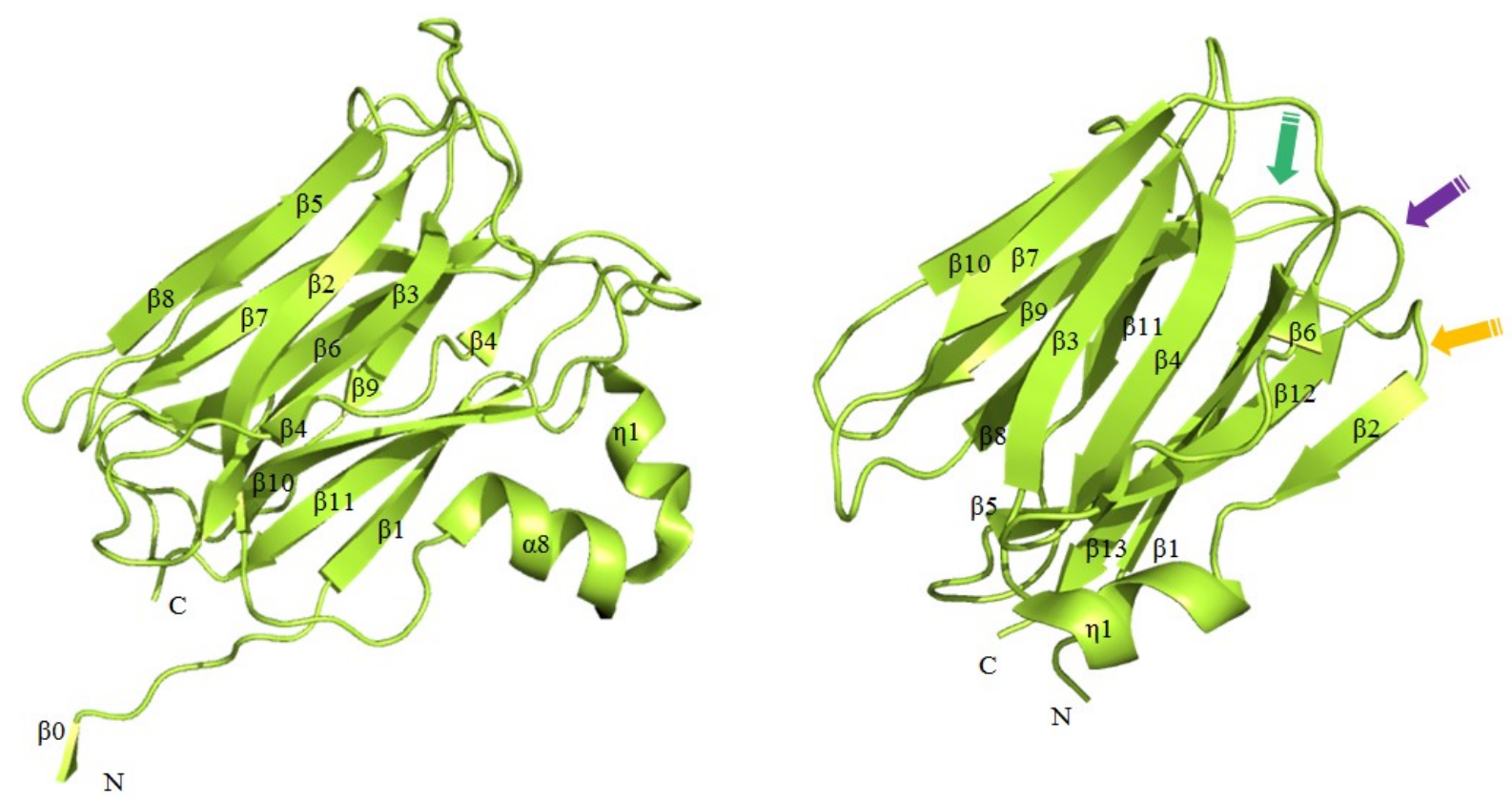
Figure 3. Cont.

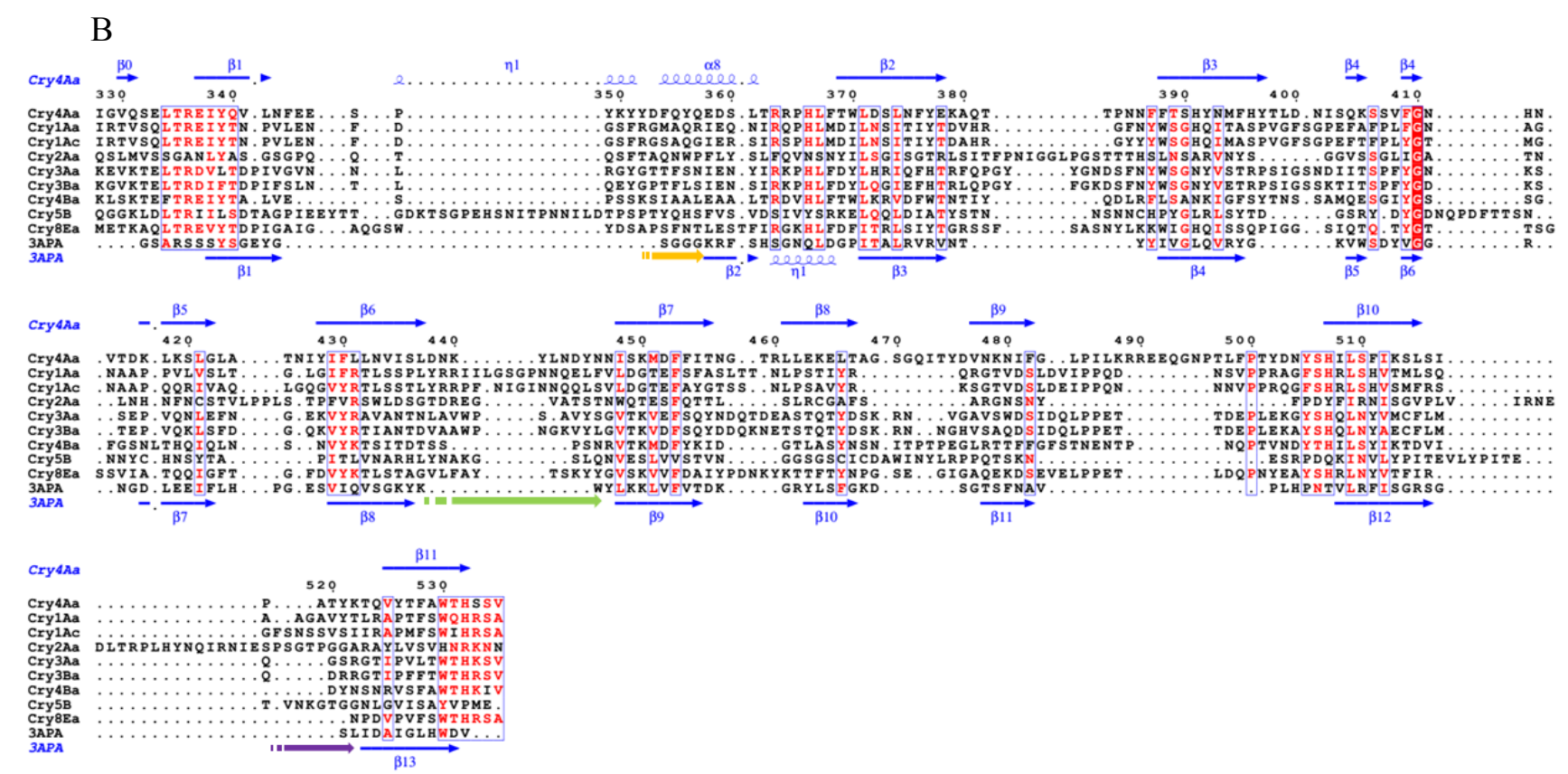

Loop residues have been targeted by site-directed mutagenesis and membrane binding assays to investigate the molecular basis of insecticidal ability [44]. Binding affinities between mutated loops and receptors have provided an elaborate explanation to the roles of loop $\beta 6-\beta 7$, loop $\beta 10-\beta 11$ and loop $\alpha 8[45,46]$. In Cry1 Ab, substitution of loop $\beta 6-\beta 7$ residue Asn372 increased the toxicity against L. dispar and enhanced binding affinity to the membrane, while by deleting the residue Asn372, toxicity and binding affinity were substantially reduced [47]. Mutants G439A and F440A in Cry1 Ab loop $\beta 10-\beta 11$ lost toxicity and binding affinities against $M$. sexta and $H$. virescens, which provided an example of interaction with the glycosyl-phosphatidylinositol(GPI)-anchored aminopeptidase-N(APN) receptor $[48,49]$. Later, two mutants in loop $\beta 6-\beta 7$ revealed that binding activity was related to APN and GPI-anchored alkaline phosphatase (ALP) receptors. Although these two mutagenic monomers were not involved in the interaction with APN or ALP, significant evidence of oligomeric Cry $1 \mathrm{Ab}$ binding to these two types of receptors was observed [50]. It has been suggested that APN and ALP were the initial receptors that promote the localization of toxin monomers into the midgut lipid raft, after that, ALP and APN would facilitate Cry toxin to form oligomer and insert into the membrane [50]. Besides APN and ALP, loop $\beta 6-\beta 7$ and loop $\alpha 8$ of Cry1Ab toxin have similar binding abilities to the cadherin-like receptor Bt- $\mathrm{R}_{1}$ from $M$. sexta [51]. Recent study has revealed that loop $\beta 10-\beta 11$ of Cry1Aa was involved in binding to BtR175, a cadherin-like protein from B. mori [52]. Also, loop $\beta 10-\beta 11$ of Cry1 Ab toxin bound to the cadherin CR12 fragments in H. virescens, while loop $\alpha 8$ and loop $\beta 6-\beta 7$ bound to $M$. sexta cadherin CR7 and CR11 fragments [51,53]. It is worth pointing out that, in Cry1 Ab, loop $\beta 10-\beta 11$ mutants could significantly affect both the binding of the oligomer with Bt $-\mathrm{R}_{1}$ and the monomer with APN in $M$. sexta [54]. Considering APN is predominantly populated in the membrane, it has been suggested that monomeric CrylAb binds with high abundance but low affinity to APN before the high affinity with cadherin receptor Bt- $\mathrm{R}_{1}[54,55]$. Therefore, a "Ping-Pong" binding model has been proposed based on binding of Cryl Ab and receptors in M. sexta: domain II loop $\beta 10-\beta 11$ may be first involved with the highly abundant but low affinity APN receptor. In the 
following, loop $\beta 6-\beta 7$, loop $\beta 10-\beta 11$ and loop $\alpha 8$ interact with cadherin receptor $B t-R_{1}$, and by this interaction, removal of helix $\alpha 1$ promotes the oligomerization. Later, the oligomeric toxin binds to APN and ALP through other regions of the Cry toxin, such as strand $\beta 16-\beta 22$ in domain III, but the oligomer remains the binding to receptor Bt- $R_{1}$. Finally, residues in loop $\beta 10-\beta 11$ participate in post-APN binding events, such as membrane insertion [54].

\subsubsection{Domain III of Three-Domain Cry Toxins}

Domain III consists of two twisted anti-parallel $\beta$-sheets forming a face-to-face sandwich, with a "jelly-roll" topology $[23,26]$ (Figure 4A). The sheet with the C-terminal strand which contacts with domain $\mathrm{I}$ is taken as the inner sheet, while the outer sheet is exposed to the solvent [28]. Although the $\beta$-strands or the connecting loops are diverse in lengths or orientations, containing three of the five conserved blocks, the most conserved domain III of Cry toxins also plays an important functional role in toxin action.

Figure 4. Structural comparison and sequence alignment of domain III of all structural known three-domain Cry toxins and CBM6 family member Aga16B-CBM6-2 binding with neoaragohexaose (PDB ID 2CDP). (A) Ribbon diagram of domain III of Cry4Aa (left) and Aga16B-CBM6-2 (right); (B) multiple sequence alignment of Cry toxins and Aga16B-CBM6-2. Secondary structure elements $\alpha$-helices, $3_{10}$-helices and $\beta$-strands are denoted in blue as $\alpha, \eta$ and $\beta$, respectively. Strictly conserved and semi-conserved residues of CBM6 family are marked in green and orange triangle, respectively.

A
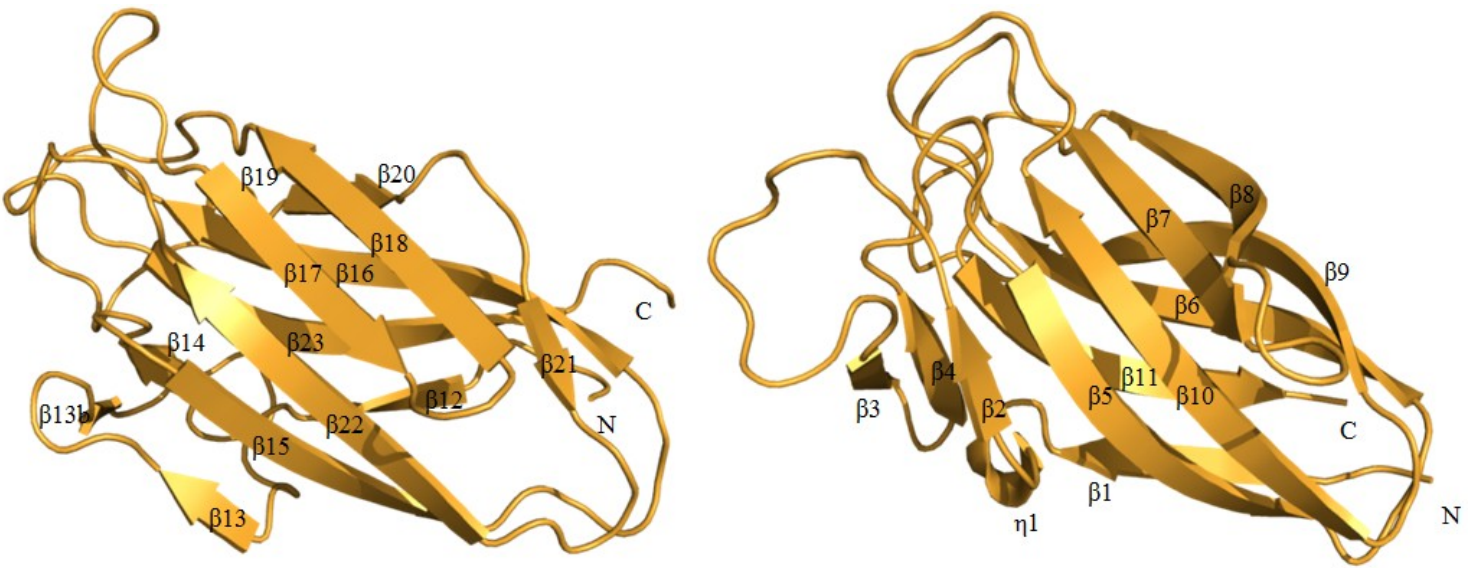

B

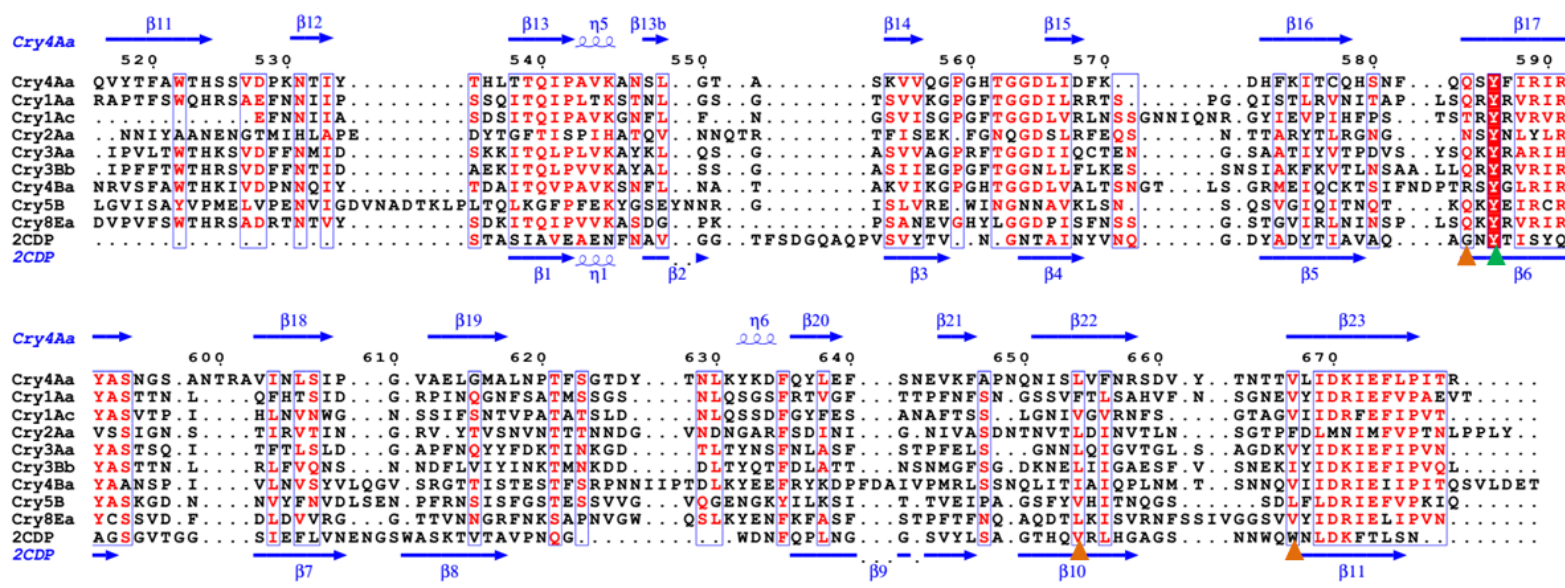


The role of domain III has been determined by various mutagenesis or recombination experiments. In H. virescens, mutants in CrylAc were able to affect receptors' binding affinities [56]. Hybrid exchanges within domain III also demonstrate the importance of specific interactions with membrane receptors. Experiments of inter-exchanged domain III between Cry1Ab and Cry1Ac or Cry1Aa and Cry1Ac have shown that domain III could be involved in both toxicity and receptor binding activity [57,58]. It was also discovered that CrylAc might have two different binding epitopes, while Cry1Aa or Cry1Ab might bind to a single site on APN [59]. Moreover, compared to loop $\beta 6-\beta 7$ and loop $\beta 10-\beta 11$ in domain II which are buried inside the oligomeric structure, strand $\beta 16-\beta 22$ region, especially strand $\beta 16$, is suggested to be involved in the oligomer binding with APN, but not responsible for pre-pore formation [46]. Mutagenesis of residues Asn506, Gln509 and Tyr513 in strand $\beta 16$ of Cry1Ac could also reduce the binding to APN in M. sexta membrane [60]. A similar observation was found at mutant T542N in loop $\beta 16-\beta 17$ within the conserved block 4 of Cry 1 Ac: the insecticidal activity was increased against $S$. exigua larvae [61]. Meanwhile, it was reported that residue Trp544 in Cry1Ac loop $\beta 18-\beta 19$ has an influence on maintaining toxin stability towards $H$. armigera [62]. Domain III exhibits not only similar functional role as domain II in receptor recognition and binding, but also insecticidal specificity and stability that could be considered as its unique feature. More adequate evidence is still needed.

In order to counter resistance or cross-resistance in transgenic crops, hybrid exchanges of domain III between Cry1C and Cry1 Ab has been proven to reduce the cross-resistance in P. gossypiella and P. xylostella, suggesting that domain III of Cry1C would be required for anti-resistance methods, while domain II of Cry1 Ab alone might have limited contribution [63]. As domain II and domain III, as well as domain I of Cry toxins are responsible for the sequential process of activation, receptor binding or oligomerization. More importantly, some particular steps are required for cooperative contributions by different domains. In-depth understanding of the structure-function relationship of Cry toxins would benefit the design of modified toxins and provide potential strategies to counter insect resistance.

\subsubsection{Structure of Three-Domain Cry Toxins in Parasporin}

In 2005, structure of parasporin-1 from B. thuringiensis stain A1190 was determined at $1.76 \AA$. It was described with limit sequence identity but significant structural similarity to the structure known in three-domain Cry toxins [64]. Of preferential anticancer cytotoxicity, parasporin-1 shows distinct biochemical features towards HeLa (Uterus gland cancer cell) cells: no obvious LDH (lactate dehydrogenase) leakage, limited fluorescence increased intensity, but remarkably, intracellular $\mathrm{Ca}^{2+}$ level rising after a few minutes of treatment [65]. It was proposed that instead of forming pores in the membrane, parasporin-1 prefers inducing cell death by an apoptotic pathway [65] (see Section 4.2.1).

Parasporin-3 (PS3Aa1 and PS3Ba1) from B. thuringiensis strain A1462 was the first reported toxin with typical three-domain architecture and is cytotoxic to human cancer cells [66]. Sequence alignment shows that parasporin-3 has the same five conserved blocks as the insecticidal three-domain Cry toxins. It has been suggested that parasporin-3 might have a similar mode of action with the three-domain Cry toxins [66]. Recent research has shown that an additional C-terminal $\beta$-trefoil ricin domain acted as the putative carbohydrate binding epitopes [67]. Meanwhile, unlike the most diverse regions that existed in domain II of Cry toxins, the C-terminal conserved domain (block 3 to block 5) 
of PS3Aa1 and PS3BA1 shows the maximum divergence, which may be responsible for the difference in their cytotoxicity preferences [66] (see Section 4.2.3).

Among newly discovered parasporins, parasporin-6 exhibits $56.4 \%$ sequence similarity with Cry 2 toxin, which suggests that its mechanism of action may be also in accordance with three-domain Cry toxins [68]. Despite the fact that the creditable crystallography evidence of these three-domain-like parasporins is still inadequate, structural and functional related work will provide an unambivalent breakthrough in the $B$. thuringiensis research area.

\subsection{Comparisons with Other Structure Known Toxins or Modules}

Based on the comparison between domain I of Cry toxins and pore-forming domain of $\alpha$-PFTs, the three-domain Cry toxin was suggested to belong to the group of $\alpha$-PFTs [69]. The $\alpha$-PFTs share a number of similarities in their pore-forming activities, which are essentially represented by colicins and Staphylococcus $\delta$-toxins (or $\delta$-haemolysins) [22]. Colicins are a family of water-soluble bacterial toxins that span lipid bilayers of $E$. coli by forming voltage-dependent channels [70]. One of the colicins, colicin A, has a three-domain architecture: a receptor binding domain that specifically binds to the outer membrane via Vitamin $\mathrm{B}_{12}$ receptor; an $\mathrm{N}$-terminal translocation domain that delivers pore-forming domain inserting into the periplasm; and a C-terminal pore-forming domain that forms a voltage-gated channel in the cytoplasmic membrane, that because of this, means it destroys the membrane potential [71-73]. The pore-forming domain of colicin A is similar to the domain I of Cry toxin and consists of ten $\alpha$-helices, with a hydrophobic hairpin (H8 and H9) in the center (Figure 2B) [70]. According to the polarity parameter valves over the helices, it has been indicated that helix $\alpha 9$ was buried inside membrane, while other surrounding helices were lay on the surface. Therefore, like Cry toxin, an umbrella model of colicin A has been concluded: the amphipathic helices $\alpha 1-\alpha 7$ and $\alpha 10$ are located on the membrane-water interface and the hydrophobic hairpin helix penetrates the membrane [71].

Structural comparison by Dali server shows a Z-score (a measure of structural similarity) as high as 11.8 between domain II of Cry toxin and the structure of ZG16p protein (PDB ID 3APA), using domain II of Cry4Aa (PDB ID 2C9K) as template [74,75]. ZG16p is a $16 \mathrm{kDa}$ secretory protein from rat pancreatic zymogen granules in cholesterol-glycosphingolipid-enriched microdomains, which was suggested to regulate the binding of aggregated zymogens to the granule membrane [76-78]. It has a $\beta$-prism fold consisting of three $\beta$-sheets, and the overall structure is similar to Jacalin-related mannose-binding-type lectins [74,79]. As the first solved structure of $\beta$-prism fold in mammalian lectins, ZG16p is made up of $12 \beta$-strands and arranges into three separated 'Greek-key' motifs. The short $\alpha$-helix between strands $\beta 2$ and $\beta 3$ is a unique feature among the $\beta$-prism fold lectins, but it also exists in Cry toxins [74]. On the top of the $\beta$-prism, three loops are proposed to be involved in sugar-binding activity: GG loop (between $\beta 1$ and $\beta 2$ ), recognition loop (between $\beta 8$ and $\beta 9$ ) and binding loop ( $\beta 12$ and $\beta 13$ ), which are similar to the receptor binding regions of loop $\alpha 8, \beta 6-\beta 7$ and $\beta 10-\beta 11$ of Cry toxins (Figure 3B). The positive-charged lysine and arginine clusters of ZG16p that are close to the putative binding related loops have shown potential interaction with mannose/glucose-type glycans and glycosaminoglycans [74]. By structural comparison with ZG16p or other $\beta$-prism fold lectin proteins, more putative sugar-binding sites of three-domain Cry toxins could be found in the future. 
When using domain III of Cry4Aa as template, Dali comparison shows a Z-score of 14.7 with Aga16B-CBM6-2, a member of carbohydrate-binding module family 6 (CBM6) from $S$. degradans (PDB ID 2CDP) [75,80]. Carbohydrate-binding module (CBM) recognizes polysaccharides, such as cellulose, chitin, starch, glycogen, xylan, $\beta$-glucans, and many other sugars such as mannan, lactose, galactose, $\beta$-D-galactosyl-1,4- $\beta$-D-N-acetylglucosamine, and blood group A/B antigens [81]. As a branch of CBM, CBM6 mainly binds to cellulose, xylan, mixed $\beta$ - $(1,3)(1,4)$-glucan, $\beta-1,3$-glucan, and agarase with different binding selectivity. It contains two carbohydrate binding clefts, which may specifically present as binding and recognition sites against its diverse substrates: cleft A locates at the loop that connects the inner and outer $\beta$-sheets of the "jelly-roll" fold; cleft B stays on the concave surface of one $\beta$-sheet [82]. Structure-based alignment within 26 CBM6 members shows a conserved $\beta$-sandwich architecture, but shares little sequence similarity within binding and recognition regions against their various binding substrates. These regions are mainly located at exposed flexible loops or adjacent $\beta$-strands. One of the only three strictly conserved residues, the aromatic residue Tyr519, is found in strand $\beta 17$ of Cry toxins (Figure 4B) [80]. The structure-function relationship of CBM6 family may provide clues to investigate why the three-domain type Cry toxins have various receptor binding specificities and toxicities towards different targets.

\subsection{Mechanism of the Three-Domain Cry Toxin}

Over the past few years, the working mechanism of Cry toxins has continuously been the key topic of research publication and academic discussion. Valuable efforts have focused on gaining a comprehensive understanding of receptor binding and membrane insertion. Based on these findings, two main models of action have been proposed.

\subsubsection{The Pore Formation Model}

The pore formation model of the three-domain Cry toxins was primarily put forward based on the interaction of Cry1 Ab and brush border membrane vesicles (BBMV) of M. sexta [18]. This model consists of several sequential steps. Crystal inclusions are firstly digested by the susceptible larvae in alkaline gut environment, where the solubilized inactive proteins are cleaved by midgut proteases at the $\mathrm{N}$ or $\mathrm{C}$ terminus into an activated protease-resistant three-domain monomer. Before membrane insertion, activated toxin binds to multiple specific receptors located on the surface of midgut membrane. In lepidopteran species such as $M$. sexta, at least two types of specific receptors are involved in binding activity. APN and ALP are supposed as the primary receptors. The activated Cry1Ab toxin first binds to APN and ALP with highly abundant but low affinity binding sites as to promote localization and concentration of the activated toxins in the midgut membrane before interacting with the second receptor of cadherin [50,83]. The interaction with cadherin facilitates proteolytic cleavage of the helix $\alpha 1$ at the $\mathrm{N}$ terminus, which induces the formation of a pre-pore oligomer [84]. Later, binding affinity is strengthened by the interactions between oligomers and APN or ALP, which consequently leads to the oligomer insertion into the membrane, causing pore formation and cell lysis (Figure 1B) [54,83,85].

In order to investigate the features of pores in the midgut cell membrane, a sequence of biochemical and biophysical experiments have been taken. However, limited by the challenges of obtaining and 
testing oligomers from water-soluble state to membrane-bound state, recent work is still lacking an unequivocal understanding of when oligomerization happens, the construction of oligomer, and the size of transmembrane pores. In the pore formation model, monomers oligomerize by sequentially binding to the specific receptors before penetrating the membrane. Whereas, the controversial evidence has questioned that Cry toxins insert into the membrane as monomers, then aggregate and assemble into oligomers within the membrane (Figure 1B). As described, Domain I of three-domain Cry toxins is believed to be required for oligomerization and pore-forming process. The proposed umbrella-like model of domain I shares an analogous model of transmembrane action with colicin A toxin [71]. Recently, the discovery of the colicin Ia toxin with the similar pore-forming domain with colicin A, has suggested a clear evidence of a multimeric state (6-8 monomers) in the lipid bilayer by Cryo-EM and image processing methods. Also, electrophysiological results have indicated a co-existence of monomer, dimer, trimer, even up to hexamer, which supported the hypothesis that colicin Ia may insert into the lipid bilayer as monomer [86]. Similar results were observed in Cry1Aa. A co-existence of monomer, dimer, trimer, and tetramer has been found during the oligomerization process of Cry1Aa, which provided the evidence that CrylAa monomer inserts into the lipid bilayer before oligomerization [87].

\subsubsection{The Signaling Pathway Model}

On the other hand, a cadherin involved alternative model has been put forward. The signaling pathway model proposes that cytotoxicity is mediated by the specific binding with cadherin receptors, which activates a $\mathrm{Mg}^{2+}$-dependent cellular signal cascade pathway that leads to the cell death [17]. Moreover, it was suggested that the specific binding to cadherin could stimulate $G$ protein and adenylylcyclase (AC), and then promote cyclic adenosine monophosphate (cAMP) concentration and activate proteins kinase A (PKA), consequently resulting in destabilization of cytoskeleton and ion channel in the membrane $[85,88]$. The pore formation model is supported by the experimental results from different insect orders, while the signaling pathway model is established on the interaction between Cry1Ab and insect High Five (H5) cell line expressing a cadherin receptor from M. sexta $[17,89,90]$. An earlier study with Sf9 lepidopteran cell line indicated that both plasma membrane permeabilization and intracellular signaling were related to Cry1C binding activity, that provided extra evidence in favor of the signaling pathway model [91]. Besides, a combination of these two models was also suggested based on the action of Cry1Ac against $H$. virescens larvae [90,92]. Signal transduction pathway could possibly be affected or triggered by sequential binding stages of Cry toxins, but it needs more detailed and reasonable evidence and analysis. As an across discipline of biochemistry, crystallography, Cryo-EM, mathematical modeling, and computational biology is emerging nowadays, applications of new technologies may contribute to a comprehensive understanding of the mechanism of action in B. thuringiensis toxins. 


\section{Cyt Toxin}

B. thuringiensis has two main toxin families, insect-specific Cry toxins and cytolytic Cyt toxins. Unlike Cry toxins, Cyt toxins show specific insecticidal activity towards dipteran insects (mosquito and black flies) in vivo but a broad range of cytotoxicity against dipteran and mammalian cells in vitro $[11,93,94]$. A distinct group of $B$. thuringiensis toxins produced by $B$. thuringiensis subsp. israelensis (Bti) is the main choice for bioinsecticide used worldwide to control mosquitoes and black flies vectors. The toxin-encoding plasmid pBtoxis from Bti has been mapped: it encodes four Cry toxins (Cry4Aa, Cry4Ba, Cry10Aa, and Cry11Aa) and three Cyt toxins (Cyt1Aa, Cyt2Ba and Cyt1Ca) [95]. Due to the functional synthesis of Cyt and Cry toxins, Bti-based commercial product is an efficient method to overcome the resistance in mosquito control.

\subsection{Structure of the Cyt Toxins}

Up until now, the known Cyt subfamily members include Cyt1 (1 Aa, 1Ab, 1Ab, 1Ac, and 1Ad), Cyt2 (2Aa, 2Ba, 2Bb, 2Bc, and 2Ca) and Cyt3Aal. They share a high level of sequence identity [6]. The monomer crystal structures of Cyt1Aa (PDB ID 3RON), Cyt2Aa (PDB ID 1CBY), and Cyt2Ba (PDB ID 2RCI) have been published (Figure 5) [96-98]. Structural similarities are observed among these three toxins. The overall structure has a single domain of $\alpha / \beta$ architecture with a $\beta$-sheet in the center surrounded by two $\alpha$-helical layers. The central $\beta$-sheet consists of six antiparallel $\beta$-strands, flanked by an $\alpha$-helix layer composed of $\alpha 1$ and $\alpha 2$ on one side and $\alpha 3-\alpha 5$ on the other [96-98]. Sequence alignment reveals that there are four blocks with high similarity scores: (I) Block 1, helix $\alpha 1$; (II) Block 2, $\alpha 5$ to $\beta 5$ region; (III) Block 3, region $\beta 6-\beta 7$; (IV) Block 4, region $\alpha 6-\beta 8$ [99]. In Cyt1Aa, hairpin $\beta 2-\beta 3$ between helices $\alpha 1$ and $\alpha 2$ is common to all members of the Cyt 1 family, but absent in the Cyt 2 group. Hairpin $\beta 6-\beta 8$ of Cyt1Aa consists of a modified 'Greek-key' topology followed by strand $\beta 4$. By comparing the $\mathrm{N}$ terminus of Cyt1Aa and Cyt2Aa, it has been revealed that an extra strand $\beta 0$ at $\mathrm{N}$-terminal end which only exists in Cyt2Aa may play an important role in dimerization and proteolytic activation [96].

\subsection{Comparisons with Other Structure Known PFTs}

Crystal structures of Cyt toxins demonstrate a significant similarity with volvatoxin 2 (VVA2) (PDB ID 1VCY) (Dali score $>20$ ), although primary sequence alignment shows very low identity (less than 17\%) (Figure 5) [75,96,97,100,101]. Volvatoxin A (VVA) is a cardiotoxic toxin isolated from edible mushroom $V$. volvacea. It can cause cardiac arrest via activation of the $\mathrm{Ca}^{2+}$-dependent ATPase in the ventricular microsomal fraction, resulting in the hemolysis of human red blood cells and cytotoxicity against tumor cells and the mitochondria of liver cells [102,103]. VVA is composed of VVA1 and VVA2, and the latter is a novel pore-forming cardiac toxin related to hemolytic and cytotoxic activity $[100,104]$. Similar to Cyt1Aa, hairpin $\beta 2-\beta 3$ of VVA2 inserts within helices $\alpha 1$ and $\alpha 2$, but this hairpin is absent from Cyt2Aa [96,97,100]. In VVA2, the amphipathic helix $\alpha 2$ at $\mathrm{N}$ terminus was thought to trigger oligomerization before penetrating the membrane, while residues 128-199 at $C$ terminus (corresponding to $\beta 5-\beta 7$ ) may be involved in membrane binding [104]. The proposed VVA2 mode of action would provide valuable insights into the action of Cyt toxins. 


\subsection{Binding Mechanism of the Cyt Toxin}

Cyt toxin does not bind to specific receptors located on the midgut epithelial cells as Cry toxin, but directly interacts with saturated membrane lipid such as phophatidylcholine, phosphatidylethanolamine and sphingomyelin [105]. Proteolytic cleavage sites are found at $\mathrm{N}$ terminus, while three major $\beta$-strands $(\beta 5, \beta 6$ and $\beta 7)$ at $C$ terminus are probably protected against proteolysis during membrane insertion [106]. Helices $\alpha 1$ and $\alpha 3$ of Cyt1Aa have been suggested to be not only involved in membrane interaction as a specificity determinant but also in intermolecular assembly [107,108]. Meanwhile, by structural comparison to the model of VVA2 that would adopt a molecular packing for pore formation, strands $\beta 5, \beta 6$, and $\beta 7$ of Cyt2Aa are long enough to span the hydrophobic region of bilayer and may oligomerize to form membrane-spanning $\beta$-barrel $[98,100]$. It has been postulated that six monomers of Cyt toxins assemble into an 'open-umbrella' conformation. Strands $\beta 5, \beta 6$ and $\beta 7$ span the lipid bilayer as the handle of an umbrella, while the top of the umbrella is made of the $\alpha$-helices, splaying on the membrane surface [99]. Therefore, based on the results of the Cyt1Aa working mechanism and crystal structure, a pore-forming model of Cyt toxins has been proposed as follows: Cyt toxin binds to the membrane as a monomer at $\mathrm{C}$-terminal region, then a conformational change at the $\mathrm{N}$ terminus triggers oligomerization that leads the $\beta$-strands spans the lipid bilayer, resulting in membrane permeabilization [105]. Contrastingly, there is another hypothesis describing that, while Cyt toxin aggregates and splays on the surface of the membrane, it destroys the lipid bilayer in a detergent-like manner [99]. These two models could relate to each other when the concentration of Cyt toxin changes. Cyt toxin may oligomerize at a low concentration, and when toxin/lipid ratio increases to a critical level, membrane could not adapt to a large number of assembled molecules and consequently breaks up into protein/lipid complexes [99].

\subsection{Mechanism of Synergism with the Cry Toxins}

Besides the membrane binding activity, Cyt toxins could also bind to Cry toxins and enhance their specific binding activities to the membrane. The synergism examples were demonstrated between Cyt and Cry11Aa or Cry4Aa from Bti [109-112]. Two epitopes of Cyt1Aa, ${ }_{196}$ EIKVSAVKE $_{204}$ (on helix $\alpha 6$ and strand $\beta 7$ ) and ${ }_{220}$ NIQSLKFAQ $_{228}$ (on strand $\beta 8$ ) are involved in the binding to Cry11Aa [96]. On the other hand, loop $\alpha 8$, strand $\beta 4$ and loop 2 (residues 386-396) of Cry11Aa are the binding epitopes interacted with Cyt1 Aa, which are the same binding regions of Cry11Aa and its receptor [110]. Additionally, two mutants K225A and K198A of Cyt1Aa, which are on the two separate epitopes, had a correlative effect on the oligomerization and pore formation of Cry11Aa [113]. This supports the finding that Cyt1Aa provides binding sites to Cry11Aa and induces the formation of oligomeric structure, which plays a similar role as the cadherin receptor in M. sexta [113,114]. Recently, Cyt1Aa mutants K198A (on strand $\beta 7$ ), E204A (on helix $\alpha 6$ ) and K225A (on strand $\beta 8$ ) on these two separate epitopes have been proved to be involved in the binding with Cry4Ba, and domain II loop $\alpha 8$ of Cry4Ba is also involved in the synergism with Cyt1Aa [111]. These results suggest that Cyt1Aa acts as a membrane receptor and synergizes with Cry4Aa or Cry11Aa from Bti at similar epitopes, which, to some extent, ensures the insecticidal toxicity of Bti more efficiently than the functional synthesis of other Cry toxins $[115,116]$. Understanding the mechanism of synergism between Cyt and Bti toxins 
might be significant to provide strategies for mosquito control, and would also provide valued experience to overcome insects' resistance to other species.

Figure 5. Structural comparison and sequence alignment of Cyt toxins and VVA2 toxin (PDB ID IVCY). (A) Ribbon diagram of Cyt1Aa and VVA2 toxins. The overall structure has a single domain of $\alpha / \beta$ architecture with a central $\beta$-sheet surrounded by two $\alpha$-helical layers. The central $\beta$-sheet consists of six antiparallel $\beta$-strands with two $\alpha$-helices on one side and three on the other; (B) multiple sequence alignment of Cyt toxins and VVA2 toxin. Secondary structure elements $\alpha$-helices, $3_{10}$-helices and $\beta$-strands are colored in blue and marked as $\alpha, \eta$ and $\beta$, respectively. The identical or semi-conserved hydrophobic residues in all sequences of the alignment are marked at the bottom with black solid circle and open circle, respectively.

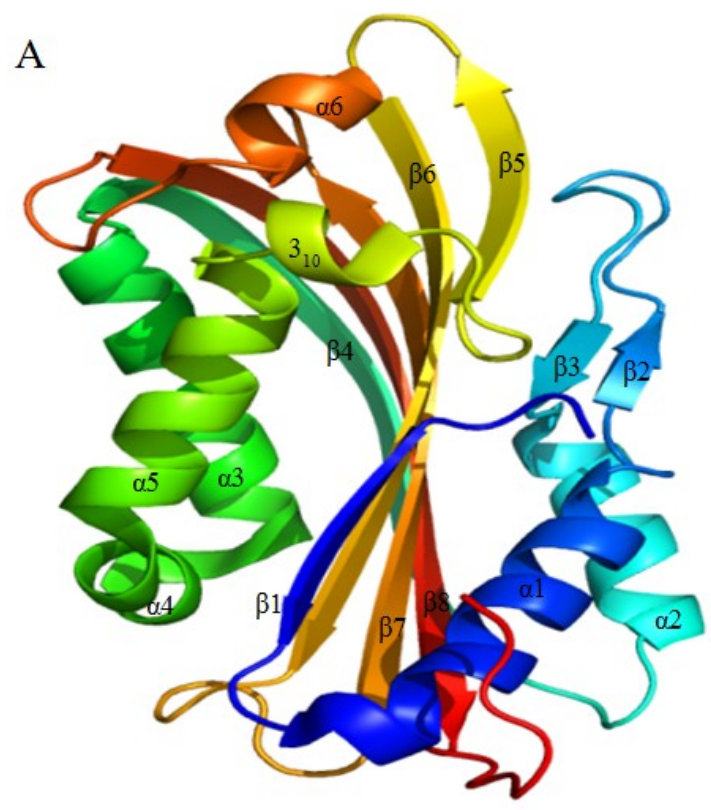

Cyt1Aa

B

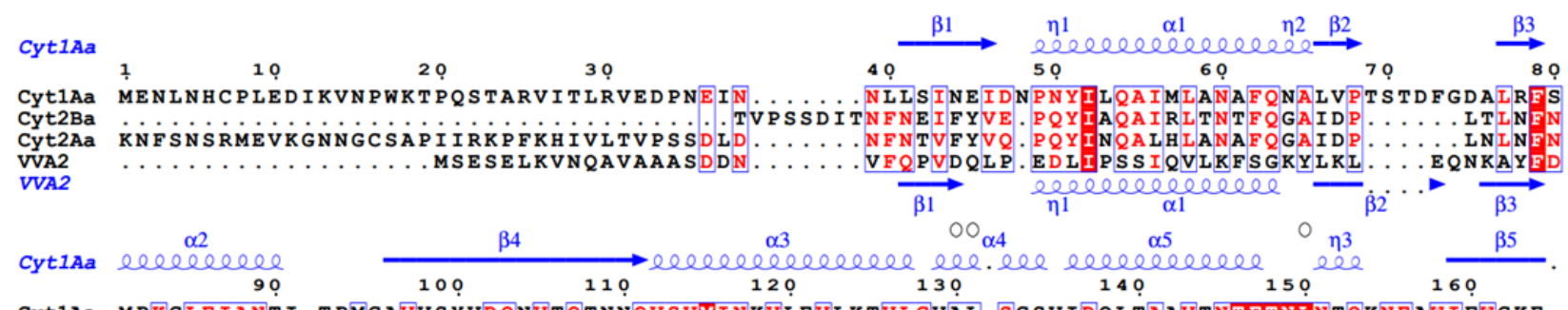

CYt1Aa MPKGLEIANTI. TPMGAVVSYVDQNVTQTNNQVSVMINKVIEVLKTVLGVAL. SGSVIDQLTAAVTNTFTNLNTQKNEAWIFWGKE.

CYT2Ba FEKALQIANGL, P. NAGVTGTINOSVIHQTIEVSVMISQIKEIIRSVLGLVINSANFWNSVVSAITNTFTNLEPQVDENWIVWRNL.

CYT2Aa FEKALQIANGI.P.NSAIVKTLNQSVIQQTVEISVMVEQLKKIIQEVLGLVINSTSFWNSVEATIKGTFTNLDTQIDEAWIFWHSL.

WVA2 WPEFKTAIDNYTGEDLSFDKYDOSTINOREOEVGSMVDKIAKFLRDAFSAVV.... DLSKLGAIIINTFTNLEEESSSGFLOFSTNN

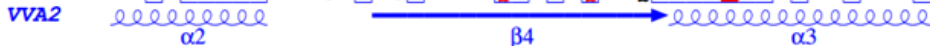

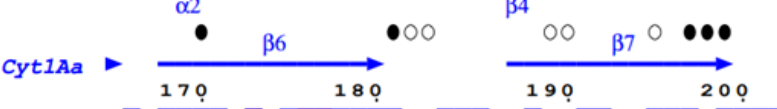

eele

$\bullet \bullet \bullet \bullet \bullet \bullet$

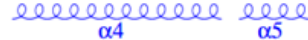

$0 \bullet 0$

210

$230 \quad 240$

CYt1Aa TANQTNYTYNVLFAIQNA. QTGGVMYCVPVGTEIKVSAV. REQVIFFTIQDSASYNVNIQSLKFAQPIVSSSQYPIADLTSAINGTI CYT2Ba SATQT SYFYKILESIQNE. DTGRFMAIIPIAFEITVDVQ. KQQLILITIKD SARYEVKMKA LTVVQAIDSYNAPIIDVF.......

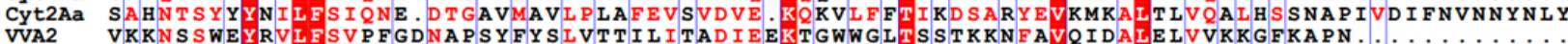
VVA2 $\beta 6$

0

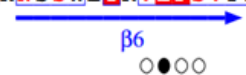

$\beta 8$ 


\section{Parasporin Toxins}

\subsection{Definition and Classification}

Recently, a novel but unique category of B. thuringiensis was discovered, and the non-insecticidal parasporal inclusions were related to an unknown biological activity [12,117]. In 1999, non-insecticidal B. thuringiensis strain A1190 (former strain 84-HS-1-11) and A1547 (former strain 90-F-45-14) were demonstrated with novel cytocidal toxicities against human cancer cells [117]. These proteins are heterogeneous in both cytotoxicity spectra and activity [12]. Up to date, six subclasses of parasporins have been recorded (PS1, PS2, PS3, PS4, PS5, and PS6), according to the homology of primary sequences by the Committee of Parasporin Classification and Nomenclature [13]. This kind of toxins exhibits strong cytotoxic activities with various toxicity spectra and levels, leading to the morphological changes of intracellular vacuolations, cell swelling and cell bursting [118,119]. Currently, research work centers on the characteristics of putative receptors and the interactions of parasporin with the cell membrane. Crystal structures of the parasporin-2 and the nontoxic $26 \mathrm{kDa}$ protein might be breaking ground and providing fundamental knowledge into receptor recognition and pore-forming mechanism.

\subsection{Cytotoxicity and Action Mechanism}

\subsubsection{Parasporin-1}

The first discovered parasporin-1 was isolated from B. thuringiensis A1190 strain (formerly 84-HS-1-11) [12,120]. In the parasporin-1 group, PS1Aa1 consisted of 15- and 56-kDa fragments and was generated by trypsin activation from $81 \mathrm{kDa}$ pro-PS1Aa1 [117]. These two fragments are tightly associated with each other as an active complex, which could not be separated even in the presence of detergent of denaturing agent. According to structural analysis, the 15- and 56-kDa fragments could be arranged into a heterodimer at a ratio of 1:1 [120]. PS1Aa1 presents strong but specific cytotoxicity towards HeLa, MOLT-4 (Leukemic T cell), HL60 cells (Promyelocytic cell), with the $\mathrm{LC}_{50}$ of 0.12 , 2.2 and $0.32 \mu \mathrm{g} / \mathrm{mL}$, respectively. Cell membrane measurement of LDH leakage assay has demonstrated that parasporin-1 did not affect membrane permeability. Also, in HeLa cells, limited changes of fluorescence concentration after being treated with paraspron-1 has shown that parasporin-1 may not form pores in the membrane. On the other site, parasporin-1 could promote $\mathrm{Ca}^{2+}$ influx from the extracellular buffer, and the G-protein inhibitor, suramin, can suppress $\mathrm{Ca}^{2+}$ influx and the cytotoxicity of parasporin-1 $[65,120]$. Therefore, it was proposed that instead of forming pores in the membrane, parasporin-1 preferred inducing cell death by an apoptotic pathway with a unique cytotoxic mechanism [65,118]. Interestingly, it was reported parasporin-1 could bind to the receptor Beclin 1 in the cell membrane [121]. In mammals, Beclin 1 exists in human breast epithelial carcinoma cell lines with limited expression, but abundant in normal breast epithelia [122]. It plays a key role in autophagy processes and is crucial in several pathways in all eukaryotic species [123]. The interaction of parasporin-1 with Beclin 1 and its cytotoxicity mechanism is waiting to be elucidated. 


\subsubsection{Parasporin-2}

Parasporin-2 was first discovered in B. thuringiensis A1547 (formerly 94-F-45-14), which belongs to $B$. thuringiensis serovar dakota (H15) [117,124]. The inactive pro-PS2Aal is approximately $37 \mathrm{kDa}$ and has limited similarity to most of the established Cry or Cyt proteins, but shares $23.5 \%$ sequence identity with Cry15Aa, which belongs to the MTX-like toxins from L. sphaericus $[125,126]$. Proteinase $\mathrm{K}$ cleaves pro-PS2Aal into a $30 \mathrm{kDa}$ active form after proteolysis at both $\mathrm{N}$ - and C-terminus $[118,119,125]$. The activated toxin shows high cytotoxicity to MOLT-4, Jurkat (Leukemic T cell), Sawano (Uterus cancel cell), and HepG2 (human hepatocyte cancer cell) with the $\mathrm{LC}_{50}$ among $10-40 \mathrm{ng} / \mathrm{mL}$. Early study proposed that parasporin-2 specifically targeted the receptor-like proteins in the membrane and induced cell damage [125]. Later, it was revealed that parasporin-2 could selectively bind to cholesterol in the human cancer cell membrane [119,127]. Experiments have demonstrated that the deletion of cholesterol may relate to a reduction in the efficiency of oligomerization. These results suggested parasporin-2 may be a lipid-raft-targeting toxin and could be transformed into a hydrophobic conformation by oligomerization, which would induce pore formation [127]. Among the candidates of parasporin-2 receptors, parasporin-2 shows a light dependence on cholesterol but an obvious requirement for GPI-anchored proteins, which are primarily located in the cholesterol and sphingolipid-enriched lipid rafts [128-130]. It is possible that the glycan region of GPI anchor may also assist parasporin-2 binding to the surface and then assembly into the membrane [130]. Accordingly, a multi-step mechanism model has been put forward: at first, parasporin-2 would bind to the GPI-anchored receptors or other proteins in the membrane; then, when toxin concentrated and oligomerized, transmembrane pores are formed, leading to damage to membrane permeability [130].

\subsubsection{Parasporin-3}

PS3Aa1 and PS3Ab1 of parasporin-3 are from B. thuringiensis stain A1462 (formerly 89-T-26-17) at a molecular weight around $88 \mathrm{kDa}[117,131]$. When treated with proteinase $\mathrm{K}$, both the $88 \mathrm{kDa}$ proteins were degraded at $\mathrm{N}$ terminus to produce the $64 \mathrm{kDa}$ activated forms. These two activated $64 \mathrm{kDa}$ proteins have narrow cytotoxicity spectra towards HL60 and HepG2 and could increase cell membrane permeability of HepG2 [66]. Primary sequence analysis revealed that they were encoded by $\operatorname{orf} 2 a$ and $\operatorname{orf} 2 b$ genes respectively and shared a high sequence homology of $88 \%$, thus the ORF2a and ORF2b proteins were correspondingly designed as PS3Aa1 and PS3Ab1. It is worth mentioning that, although parasporin-3 has a very low sequence similarity with Cry or Cyt toxins, the five typical conserved block regions of the three-domain Cry toxin exist within this group [66]. Based on this, parasporin-3 probably follows the similar receptor-binding model in target cells $[66,118]$.

\subsubsection{Parasporin-4}

Parasporin-4 was isolated from the soil isolate B. thuringiensis A1470 strain (formerly 89-T-34-22), belonging to the serovar shandongiensis [132,133]. When digested with proteinase $\mathrm{K}$, an activated $27 \mathrm{kDa}$ protein was isolated and showed strong cytotoxicity against human cancer cells in vitro, such as MOLT-4, CACO-2 (human colon cancer), Sawano, TCS (human uterus cervix cancer), and HL60 cells [132-137]. Research has revealed that parasporin-4 nonspecifically binds to the plasma 
membrane, forming an oligomeric pore complex in target cells. During this process, it shows a cholesterol-independent activity, which is distinct from parasporin-2 that requires cholesterol for the cytotoxic activity $[130,138]$. On the other hand, PSI-BLAST search results have presented that parasporin-4 shares homologies with Cry15Aa, $\alpha$-toxin, aerolysin, and $\varepsilon$-toxin at sequence identities of $24 \%, 15 \%, 10 \%$, and $21 \%$, respectively. Moreover, a CD spectrum of parasporin- 4 revealed that it contains $51 \%$ of $\beta$-structure. Thus, parasporin- 4 could be a unique cholesterol-independent $\beta$-PFT, while the identification of specific receptor and its transmembrane mechanism need to be addressed [138].

\subsubsection{Other Parasporins}

Parasporin-5 from B. thuringiensis A1100 strain was discovered by Ekino and Shin [13]. Parasporin-6 (CP84 toxin) was isolated from B. thuringiensis strain M019, which exhibits 56.4\% sequence similarity to the three-domain Cry toxin. It may have extra peptide regions in the third domain. Parasporin-6 shows preferential cytotoxicity towards HepG2 and HeLa cells, with LC $_{50}$ at $2.3 \mu \mathrm{g} / \mathrm{mL}$ and $7.2 \mu \mathrm{g} / \mathrm{mL}$, respectively, which are lower than the toxicities of parasporin-1 and parasporin-2 against their corresponding human cancer cells [68,120,125].

\subsection{Structure of Parasporins and Other Aerolysin Family Members}

Since the first structure of proaerolysin toxin was solved in 1994, aerolysin-type toxins have been described as newly discovered category and have become the second largest family of PFTs after Cholesterol Dependent Cytolysins (CDCs) [139,140]. This diverse family originates from Gram-positive and Gram-negative bacteria in plants and eukaryotes, which contains but is not limited to: (1) Aerolysin, from A. hydrophila and related Aeromonas species; (2) C. septicum epsilon-toxin and enterotoxin from $C$. perfringens; (3) Alpha-toxin ( $\alpha$-toxin) from C. septicum; (4) Enterolobin from E. contorisiliquum; (5) mosquitocidal toxins (MTx) from L. sphaericus; (6) anti-cancer parasporin-2 toxin from B. thuringiensis; (7) L. sulphureus lectin (LSL); and (8) Hydralysins from aquatic animals in the phylum Cnidaria [140-142]. Aerolysin-type toxins have remarkable sequence identity or structural similarity among their domains, and also act as cytolysins via pore-formation [141].

The crystal structures of parasporin-2 (PDB ID 2ZTB) and the nontoxic $26 \mathrm{kDa}$ protein (PDB ID 2D42) were determined recently, the latter of which was a nontoxic protein from $B$. thuringiensis A1470 and shared 38\% sequence identity with parasporin-4 [126,143,144]. An automated comparative structure of parasporin-4 is generated by SWISS-MODEL, using the nontoxic $26 \mathrm{kDa}$ protein as template (Figure 6) [145]. A significant structural similarity is found within these structures to the aerolysin-type $\beta$-PFTs.

\subsubsection{Structure of the Aerolysin-Type Parasporin}

\subsubsection{Domain I of the Aerolysin-Type Parasporin}

Domain I was suggested to play an important role in the binding interaction with GPI anchors [146]. The $\alpha$-helices are existed only in this domain: four short $\alpha$-helices in parasporin- 2 while only two separated $\alpha$-helices in the nontoxic $26 \mathrm{kDa}$ protein. In domain I, N-terminal strands makes up a short $\beta$-hairpin (S2 and S3 in parasporin-2; S9 and S10 in the nontoxic $26 \mathrm{kDa}$ protein) and $\mathrm{C}$ terminus 
includes a part of the longest spanning $\beta$-strand (S11 in parasporin-2; S9 in the nontoxic $26 \mathrm{kDa}$ protein). In domain I of aerolysin-type $\beta$-PFTs, aromatic residues are abundant. Those aromatic residues could bind to carbohydrates, as galactose and glucose complex: the aromatic rings stack with planar faces of carbohydrate rings via protein-carbohydrate interactions. The interaction between aromatic residues and carbohydrates is determined by the relative position and orientation, which could contribute to the various binding specificity of the sugar-binding proteins [147]. By the structural comparisons, domain I of structural modeled parasporin-4 may have shorter $\beta$-strands, which is distinct from the nontoxic $26 \mathrm{kDa}$ protein but similar to parasporin-2. It could be assumed that in the nontoxic $26 \mathrm{kDa}$ protein, the long antiparallel $\beta$-strands may protect potential residues from exposure to the solvent, thus blocking the interaction with membrane.

\subsubsection{Domain II of the $\beta$-PFT Type Parasporin}

Domain II of parasporin-2 and the nontoxic $26 \mathrm{kDa}$ protein shows highly similarity, which has one $\beta$-hairpin and one anti-parallel five-stranded $\beta$-sheet $[126,143]$. In parasporin-2, strand S1 and the five-stranded $\beta$-sheet are rearranged to form a four-stranded $\beta$-sheet near the boundary to domain I, which associates with the helices of domain I by hydrophobic interactions. Inner surface of the $\beta$-sheet and the amphipathic $\beta$-hairpin makes up a hydrophobic core, surrounded by the hydrophilic residues on the $\beta$-sheet and stabilized by the hydrogen bonds [126]. Arrangement of hydrophobic and hydrophilic residues is a critical feature to direct protein to fold [148]. In the aerolysin-based structural model of $\alpha$-toxin, the amphipathic $\beta$-hairpin could span the membrane and is necessary for pore formation [149]. Also, site-directed mutagenesis in amphipathic $\beta$-stand of ETX could alter channel characteristics in lipid bilayer. This suggested that domain II of ETX could be involved in membrane insertion and pore formation [150]. Unlike the nontoxic $26 \mathrm{kDa}$ protein, strands adjacent to the amphipathic $\beta$-hairpin in parasporin-2 (strand S4 and S5) and modeled parasporin-4 are separated by loops; it could be deduced that the separated $\beta$-strands may be more flexible to facilitate the amphipathic $\beta$-hairpin unfold and stretch during the transmembrane process. In addition, parasporin-2 has a remarkable distribution of hydrophobic serine and threonine residues in the $\beta$-strands adjacent to the amphipathic $\beta$-hairpin in domain II [126]. Similar serine- and threonine-rich flanking sequences are also found in other structural known aerolysin-type $\beta$-PFTs, such as ETX, aerolysin, $\alpha$-toxin, and MTXs [146]. These sequences were proposed to participate in the transmembrane process $[126,146]$.

\subsubsection{Domain III of the $\beta$-PFT Type Parasporin}

Domain III of parasporin-2 and the nontoxic $26 \mathrm{kDa}$ protein consists of an anti-parallel three-stranded $\beta$-sheet and an anti-parallel two-stranded $\beta$-sheet, packed as a $\beta$-sandwich, $[126,143]$. As C-terminal end of parasporin-2 may be removed during proteolytic digestion, some part of the buried hydrophobic core within the $\beta$-sandwich is exposed to the solvent, forming a small hydrophobic surface patch along the $\beta$-strands. It was suggested that $\mathrm{C}$-terminal activation would be required for oligomerization [126]. 
Figure 6. Structural comparison among parasporin-2, the nontoxic $26 \mathrm{kDa}$ protein and the aerolysin-type $\beta$-PFTs. The membrane binding related $\mathrm{N}$-domain is colored in pale green. Membrane insertion and pore formation regions are colored in lemon and bright orange, respectively [142]. The pink colored amphipathic $\beta$-hairpin is suggested to be responsible for pore formation. Parasporin-4 is modeled using the nontoxic $26 \mathrm{kDa}$ protein as template.

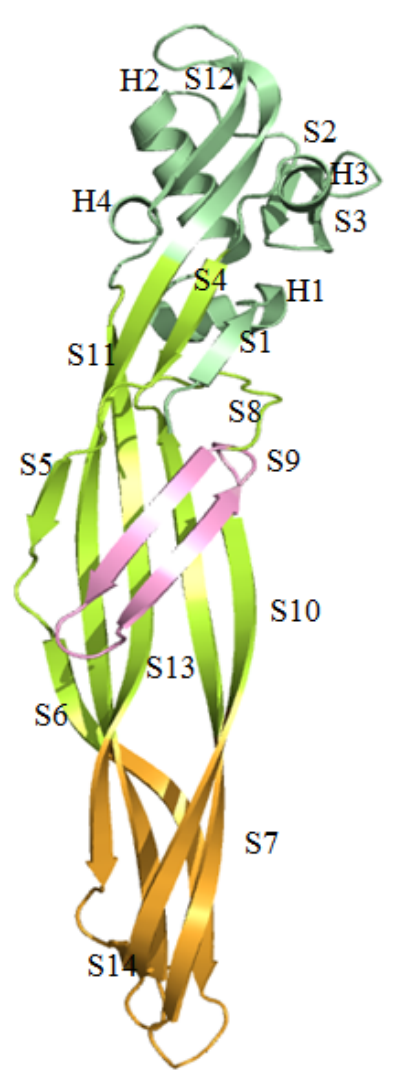

Parasporin-2

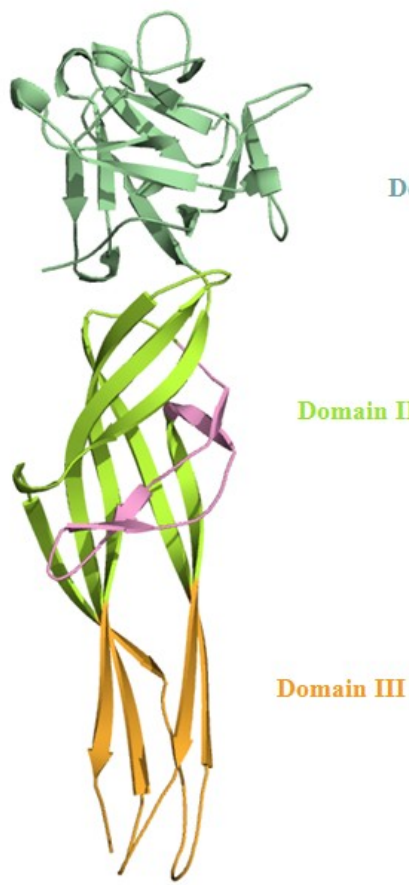

Clostridium perfringens

Enterotoxin

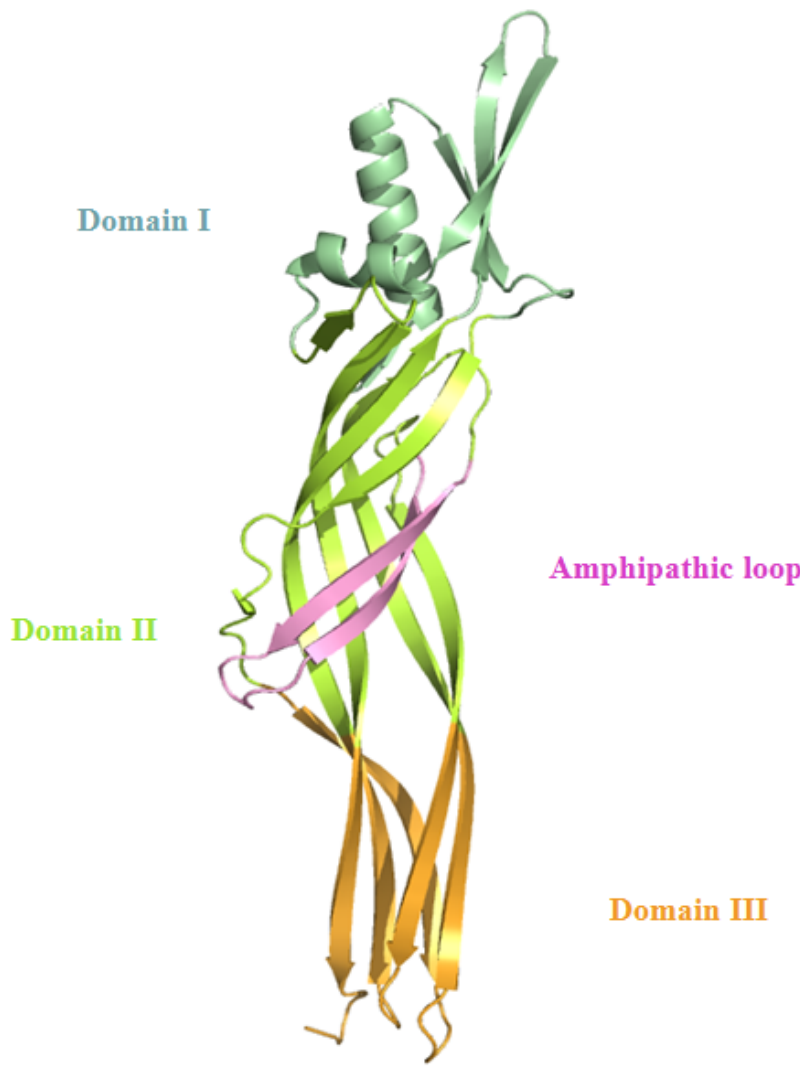

Nontoxic $26 \mathrm{kDa}$ protein

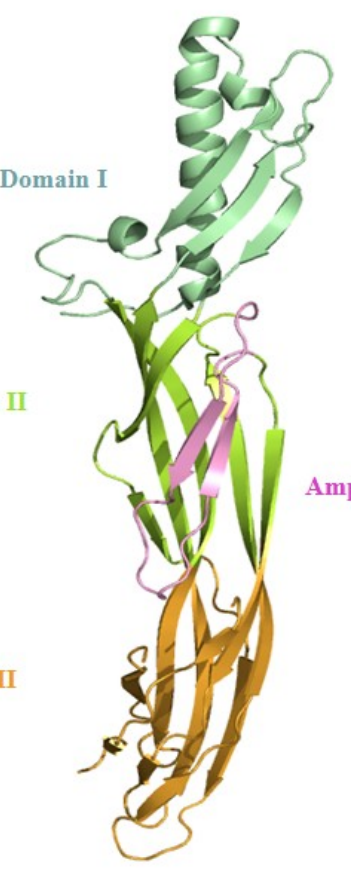

Clostridium perfringens

Epsilon toxin

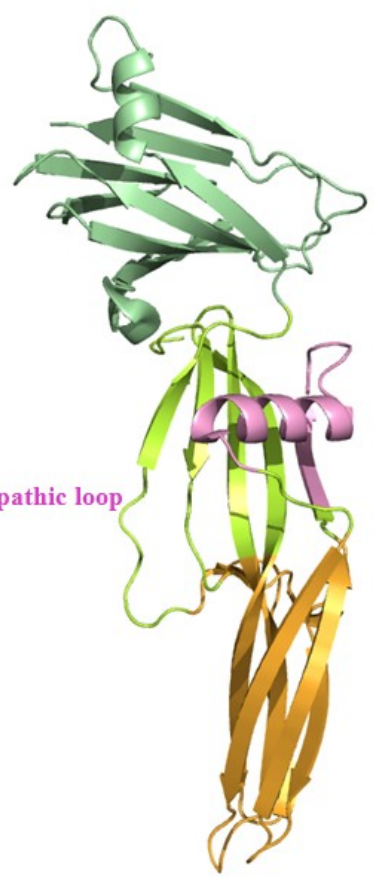

Lacctiportus sulphureus

Lectin

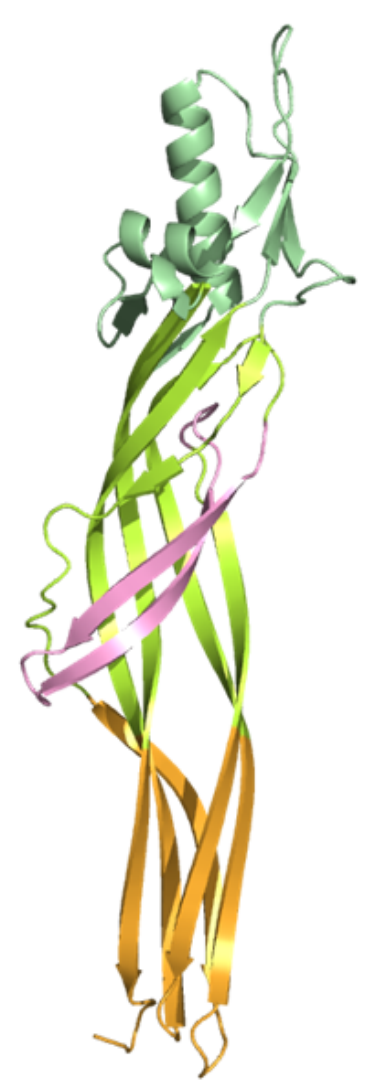

Modeled Parasporin-4

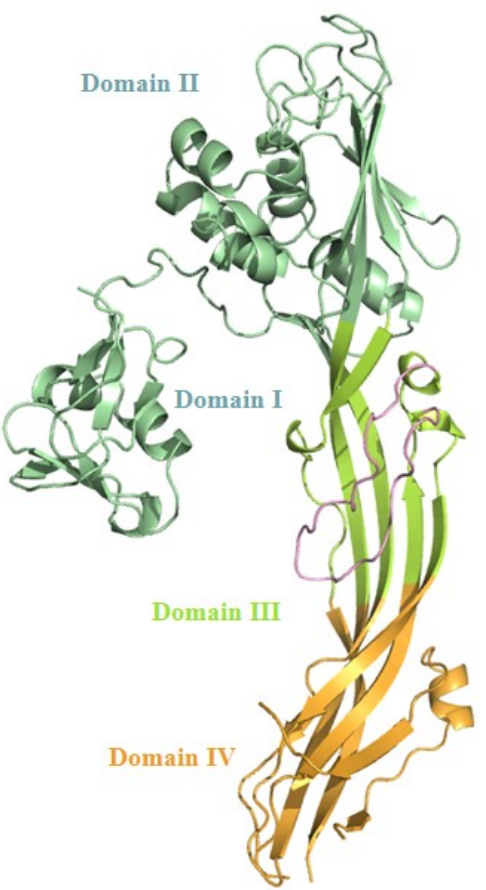

Aeromonas hydrophila

Proaerolysin 


\subsubsection{Comparisons with Other Structure Known Toxins in Aerolysin Family}

Using parasporin-2 as a template, several structures with high similarity are found by DALI server: Z-score of ETX, nontoxic $26 \mathrm{kDa}$ protein, LSL, proaerolysin, and CPE are 10.0, 9.7, 6.5, 6.3 and 5.5, respectively $[75,126,139,142,143,146,151]$. Based on structural homology and biological relevance, parasporin-2 was proposed as a new member of aerolysin-type $\beta$-PFTs [126]. Structural comparisons among aerolysin family members present similarities within domain III and domain IV of aerolysin, domain II and domain III of parasporin-2, ETX, CPE, and LSL, these domains are suggested to be related to oligomerization and responsible for pore formation. Meanwhile, receptor binding related domain I of parasporin-2, ETX, CPE, and LSL and domain II of aerolysin exhibit limited structural similarity.

\subsubsection{The Most Diverse Domain}

Domain I and domain II of aerolysin, and domain I of other members from aerolysin family present the most structural diversity. Differences within these regions probably result in the variation of receptor recognition and toxicity specificity (Table 2). In the newly released structure of CPE, domain I could bind to claudin receptors via the residues exposed on the surface [142,152]. Unlike CPE, domain II of aerolysin monomer may participate in the binding to the GPI-anchored receptors [141,153]. Similar evidence was found in parasporin-2 that GPI-anchored proteins are involved in cytocidal specificity and oligomerization [130]. Although with the most diversity, these regions exhibit several interesting features in common. In aerolysin, aromatic residues are abundant on the surface of domain II, and nearly $70 \%$ of the aromatic residues within the whole structure are solvent accessible [139]. Similar aromatic clusters are also found in ETX, LSL and parasporin-2. In parasporin-2, aromatic residues (tryptophan, histidine, phenylalanine, and tyrosine) of domain I display an obvious patch on the surface [126]. The surface-exposed aromatic rings have been recognized as binding determinant to polysaccharides, while this carbohydrate-aromatic stacking is frequently found in carbohydrate-protein complex [154]. In particular, orientation of the aromatic rings may play a major role in specific binding ability [155]. At the $\mathrm{N}$ terminus of LSL, aromatic residues (Tyr91/Phe139 and Asp93/Asp141) in the lectin $\beta$-trefoil architecture are involved in carbohydrate binding: residues Tyr91 and Phe139 are stacking against the galactose ring of $\mathrm{N}$-acetyllactosamine; side chains of residues Asp93 and Asp141 interact with axial C4 hydroxyl group of galactose by hydrogen bonds [156]. The function of aromatic residues still remains to be demonstrated in parasporin; however, distributions of these surface residues may provide specific interactions with the membrane. 
Table 2. Characteristics of parasporin proteins and aerolysin-type PFTs *.

\begin{tabular}{|c|c|c|c|c|c|c|c|c|}
\hline Toxins & Strain & PDB ID & $\begin{array}{c}\text { Native } \\
\text { Size in kDa }\end{array}$ & Cytotoxicity & Receptor Characteristics & $\begin{array}{c}\text { Pore } \\
\text { Formation }\end{array}$ & $\begin{array}{c}\text { Oligomerization } \\
\text { (number of } \\
\text { monomers) }\end{array}$ & Toxin Type \\
\hline Parasporin-1 & B. thuringiensis A1190 & unkown & 81 & Hela, MOLT-4, Hep G2, HL-60 & Beclin-1 & unknown & unknown & $\begin{array}{c}\text { three-domain-type } \\
\text { Cry toxin }\end{array}$ \\
\hline Parasporin-2 & B. thuringiensis A1547 & 2ZTB & 37 & $\begin{array}{c}\text { MOLT-4, Jurkat, Sawano, } \\
\text { HL-60, and HepG2 }\end{array}$ & $\begin{array}{l}\text { require GPI-anchored } \\
\text { protein }\end{array}$ & possibly & unknown & $\begin{array}{c}\text { Aerolysin-type } \\
\beta \text {-PFT }\end{array}$ \\
\hline Parasporin-3 & B. thuringiensis A1462 & - & 88 & HL-60, HepG2 & unknown & unknown & unknown & $\begin{array}{c}\text { three-domain-type Cry } \\
\text { toxin }\end{array}$ \\
\hline Parasporin-4 & B. thuringiensis A1470 & - & 34 & $\begin{array}{c}\text { MOLT-4, HL-60, HepH2, } \\
\text { Caco-2, Sawano, TCS }\end{array}$ & cholesterol-dependent & possibly & unknown & $\begin{array}{c}\text { cholesterol-independen } \\
\beta \text {-PFT }\end{array}$ \\
\hline $\begin{array}{c}\text { nontoxic } \\
26 \mathrm{kDa} \text { protein }\end{array}$ & B. thuringiensis A1470 & $2 \mathrm{D} 42$ & 32 & nontoxic & unknown & unknown & unknown & $\begin{array}{c}\text { nontoxic Aerolysin-type } \\
\beta \text {-PFT }\end{array}$ \\
\hline Aerolysin & Aeromonas hydrophila & 1PRE & 52 & $\begin{array}{c}\text { broad range with GPI-anchored } \\
\text { epithelia cells }\end{array}$ & $\begin{array}{l}\text { GPI-anchored } \\
\text { receptors }\end{array}$ & yes & 7 & $\begin{array}{c}\text { Aerolysin-type } \\
\quad \beta \text {-PFT }\end{array}$ \\
\hline Epsilon & Clostridium perfringens & $1 \mathrm{UYJ}$ & 32.5 & limit cell lines as MDCK, G-402 & $\begin{array}{l}\text { non GPI-anchored } \\
\text { membrane protein }\end{array}$ & yes & 7 & $\begin{array}{c}\text { Aerolysin-type } \\
\beta \text {-PFT }\end{array}$ \\
\hline Entertoxin & Clostridium perfringens & 2XH6 & 35 & $\begin{array}{c}\text { intestinal } \\
\text { epithelia cells }\end{array}$ & Claudi & yes & $3 / 6$ & $\begin{array}{c}\text { Aerolysin-type } \\
\quad \beta \text {-PFT }\end{array}$ \\
\hline LSL & Laetiportus sulphureus & $1 \mathrm{~W} 3 \mathrm{~A}$ & 35 & unknown & glycoproteins & possibly & $4 / 6$ & $\begin{array}{c}\text { Aerolysin-type } \\
\quad \beta \text {-PFT }\end{array}$ \\
\hline
\end{tabular}

* Table 2 is concluded and modified according to Ref. [118,141]. 


\subsubsection{The Pore-Forming Domain}

Some features of the pore-forming domain in aerolysin-type PFTs are shared in common. First of all, the amphipathic $\beta$-hairpin (or loop) resides in the center of the pore-forming domain. It is plausible that this long $\beta$-hairpin spans the lipid bilayer and forms the transmembrane $\beta$-barrel in the membrane [157]. When the $\beta$-hairpin penetrates the lipid bilayer, as the transmembrane stage take places, the relevant structure would fold or collapse accordingly [152]. Secondly, compared to the surface features of the most diverse domain in the aerolysin family, aromatics residues also cluster at the amphipathic $\beta$-hairpin (or loop) and inner surface of the $\beta$-sheet [156]. Little is known about these aromatic residues. However, adjacent to the amphipathic $\beta$-hairpin (or loop), these residues may take part in the connection with the membrane during the pore formation. In parasporin-2, it was pointed out that the side chain of phenylalanine residue would face towards the membrane and act as an anchor [126]. Thirdly, besides the aromatic residues, serine and threonine residues present a striking distribution on the surface. In ETX, serine and threonine residues are abundant at both sides of the amphipathic loop. It was inferred that serine and threonine residues may be related to the oligomerization [146]. Particularly, it was also believed that after receptor binding but before the pore-forming process, serine and threonine residues may assist the $\beta$-hairpin rearrangement and insertion but keep the molecule parallel to the membrane [130]. Last but not the least, like the three-domain Cry toxins, after secretion, the water-soluble native aerolysin-type toxins would turn into activated stage by proteolytic digestion at the sequence terminal. Similar to other toxins, parasporin-2 retains its original tertiary conformation after $\mathrm{N}$ - or/and $\mathrm{C}$-terminal digestion. The $\mathrm{N}$ terminus of parasporin-2 resides between the amphipathic $\beta$-hairpin and the $\beta$-strand $\mathrm{S} 4$. It was supposed that $\mathrm{N}$ terminus may block the transmembrane $\beta$-hairpin spanning the membrane, consequently preventing pore formation. The estimated $\mathrm{C}$ terminus of parasporin-2 probably consists of a $\beta$-strand and $\alpha$-helix that may protect and cover the exposed hydrophobic part of domain III [126]. In aerolysin, the cleaved C-terminal peptide is not involved in pore formation, but may guide the activated monomer's rearrangement into oligomers [158,159]. It could be estimated that when $\mathrm{C}$ terminus of parasporin is cleaved from the native toxin, the exposed hydrophobic region may facilitate the transmembrane $\beta$-hairpin to fold and then insert into the membrane.

\subsubsection{Membrane Insertion Mechanism}

In 1994, when the X-ray structure of proaerolysin was published, a pore-forming model of aerolysin was built [139]. It is the first time that the transmembrane model of aerolysin-type PFTs was demonstrated. Seven monomers of activated aerolysin grouped into a heptamer without obvious conformational changes and inserted into the membrane [160]. Then, with the help of Cryo-EM and the three-dimensional reconstruction method, it was observed that an aerolysin mutant Y221G could form a water-soluble mushroom-shaped heptamer. In this model, the whole domain IV spans the membrane as the stem region in the lipid bilayer [161]. Later, a rivet-like model was put forward. It was proposed that the amphipathic $\beta$-hairpin could play a role in transmembrane procedure, and penetrate the lipid bilayer as a requirement for membrane insertion but not for heptamerization. The hydrophobic tips of the amphipathic loop would fold back towards the channel, and parallel to the 
plane of the membrane, like an upside-down rivet [162]. The rivet-like model describes a transmembrane stage of the aerolysin heptamer, which is mainly caused by the reorganized amphipathic $\beta$-hairpin. Recently, a new membrane insertion model was presented based on the combined technologies of Cryo-EM, X-ray crystallography, molecular dynamics, and computational modeling [159]. When proaerolysin monomer firstly interacts with the membrane, domain II would bind to the GPI-anchored receptors, indicating domain II is facing the membrane and the entire toxin is $180^{\circ}$ rotated. Later, monomers assemble into a heptamer by proteolytic activation at the $\mathrm{C}$ terminus of domain IV. During the heptamerization, domain II retains the binding with GPI-anchored receptors. Therefore, the pre-pore structure is achieved by a $180^{\circ}$ rotated rearrangement from a mushroom-shape into a disk-like heptamer. In the following transmembrane steps, the amphipathic loop of domain III swirls and rearranges into a $\beta$-hairpin, then combines with the neighboring loops of the pore-pore heptamer into a transmembrane $\beta$-barrel (Figure 7). The swirling transmembrane model is consistent with the available structural and biochemical data, and is recognized as the actual membrane insertion process $[159,163]$. This model offers us a beautiful example with key procedures during membrane insertion. Although the fundamental working mechanism and membrane penetration features are varied in aerolysin family members, the elucidated transmembrane models of aerolysin have provided valuable insights that will be explored and identified in other aerolysin-type PFTs in the future.

Figure 7. Transmembrane model of aerolysin in lipid bilayer (modified according to Ref [159]). Domain I and domain II of aerolysin are colored in orange; domain III in lemon; domain IV in pale green; and the amphipathic loop in pink. According to the aerolysin swirling model, receptor binding and transmembrane steps are as follows: 1. Solubilized aerolysin binds to the GPI-anchored receptors in the lipid rafts at $\mathrm{N}$-terminus. This process facilitates aerolysin monomer a $180^{\circ}$ rotation to make its $\mathrm{N}$-terminal end facing the membrane. 2. After C-terminal proteolytic digestion, the activated aerolysin monomers assemble into a heptamer, as well as the $\mathrm{N}$ terminus of aerolysin remains binding to receptors during oligomerization. 3. The amphipathic loop of domain II swirls and rearranges into a transmembrane $\beta$-barrel.

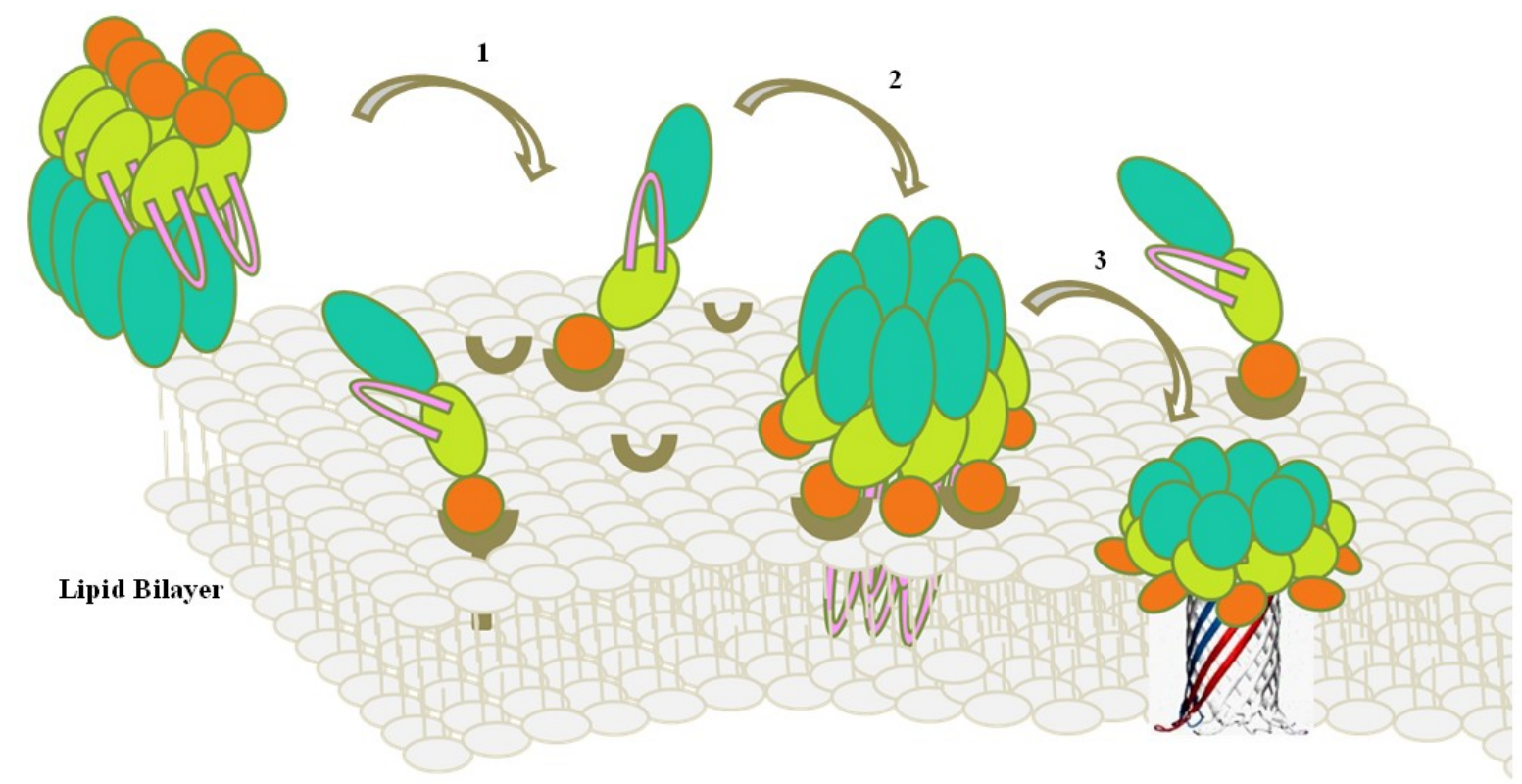




\section{Conclusions}

Based on known or predicted structures and structure-function relationships, we describe B. thuringiensis Cry, Cyt and parasporin toxins into three different categories: three-domain type $\alpha$-PFTs, Cyt toxin type $\beta$-PFTs and aerolysin type $\beta$-PFTs. By inter- and inner-comparison among B. thuringiensis toxins and PFTs or other structural related protein, an apparent outline of structural and functional features within these three groups has been drawn. Although numerous researches have been dedicated to investigating the role of specific structural components, and many clear interactions between membrane and toxins have been described, the mechanism of action still remains controversial, and there is still a long way to go before it can be elucidated unequivocally. Nevertheless, because of these contributions, applications of B. thuringiensis toxin and strategies for overcoming resistance or cross-resistance have developed rapidly.

It is also worth mentioning that some toxins have been suggested with unique toxicities and possible distinct structures. As Cry6A, a nematicidal toxin shows low similarity to the three-domain Cry toxins and is lacking any of the five conserved blocks [32,164]. Cry22A and Cry34/Cry35 binary toxin have also been estimated with diverse structural characteristics $[14,165,166]$. As the number of discovered toxins rises, and novel structures are being solved, a new member of $B$. thuringiensis toxins would be described under these three categories or even according to other unidentified groups in the future. Comprehensive understanding of current structural related features may deepen the knowledge of novel toxins and accelerate the development of novel products in pest management and human health care.

Moreover, primary sequences and structural similarity have predicted an evolutionary approach within B. thuringiensis toxins [14]. On the other hand, evolutionary changes of individual amino acid residues could alter protein binding interactions and secondary elements, resulting in various specific toxicities and different tertiary structures. Upon structural analysis of Cry, Cyt and parasporin toxins, however, it could be hypothesized that an inner-molecular domain shift (e.g., domain I of three-domain Cry toxin and aerolysin-type parasporin) or domain insertion/deletion (e.g., $\beta$-sheet of Cyt toxin) may take place during the evolutionary process, which consequently causes structural and functional divergence of $B$. thuringiensis toxins.

\section{Acknowledgments}

We thank Dayong Zhou for his thorough and critical review of this manuscript. This work is supported by the National Basic Research Program of China (973 Program, Grant No. 2013CB127504) and the State Key Program of National Natural Science of China (Grant No. 30930004).

\section{Author Contributions}

The manuscript presented here was carried out in collaboration of all authors. Chengchen $\mathrm{Xu}$ prepared the majority of the manuscript. Ziniu Yu selected the publications for reviewing the structural progress in B. thuringiensis toxins. Bi-Cheng Wang, Ziniu $\mathrm{Yu}$ and Ming Sun supervised the preparation process of the manuscript and provided critical feedback. 


\section{Conflicts of Interest}

The authors declare no conflict of interest.

\section{References}

1. Didelot, X.; Barker, M.; Falush, D.; Priest, F.G. Evolution of pathogenicity in the Bacillus cereus group. Syst. Appl. Microbiol. 2009, 32, 81-90.

2. Schinepf, E.; Crickmore, N.; van Rie, J.; Lereclus, D.; Baum, B.; Feitelson, J.; Zeigler, D.R.; Dean, D.H. Bacillus thuringiensis and its pesticidal crystal proteins. Microbiol. Mol. Biol. Rev. 1998, 62, 775-806.

3. Nester, E.W.; Thomashow, L.S.; Metz, M. 100 Years of Bacillus thuringiensis: A Critical Scientific Assessment; American Society for Microbiology (ASM): Washington, DC, USA, 2002.

4. Khyami-Horani, H.; Hajaij, M.; Charles, J.F. Characterization of Bacillus thuringiensis ser. jordanica (Serotype H71), a novel serovariety isolated in Jordan. Curr. Microbiol. 2003, 47, 26-31.

5. De Barjac, H.; Bonnefoi, A. Essai de classification biochimique et sérologique de 24 souches de Bacillus du type B. thuringiensis. Entomophaga 1962, 7, 5-31. (In French)

6. Crickmore, N.; Zeigler, D.R.; Schnepf, E.; van Rie, J.; Lereclus, D.; Baum, J.; Bravo, A.; Dean, D.H. Bacillus thuringiensis Toxin Nomenclature. Available online: http://www.lifesci.sussex.ac.uk/ home/Neil_Crickmore/Bt (accessed on 3 September 2014).

7. Gao, M.; Li, R.; Dai, S.; Wu, Y.; Yi, D. Diversity of Bacillus thuringiensis strains from soil in China and their pesticidal activities. Biol. Control 2008, 44, 380-388.

8. Zhong, C.; Ellar, D.J.; Bishop, A.; Johnson, C.; Lin, S.; Hart, E.R. Characterization of a Bacillus thuringiensis $\delta$-endotoxin which is toxic to insects in three orders. J. Invertebr. Pathol. 2000, 76, 131-139.

9. Haider, M.Z.; Ward, E.S.; Ellar, D.J. Cloning and heterologous expression of an insecticidal delta-endotoxin gene from Bacillus thuringiensis var. aizawai ICI toxic to both lepidoptera and diptera. Gene 1987, 52, 285-290.

10. Crickmore, N.; Zeigler, D.R.; Feitelson, J.; Schnepf, E.; van Rie, J.; Lereclus, D.; Baum, J.; Dean, D.H. Revision of the nomenclature for the Bacillus thuringiensis pesticidal crystal proteins. Microbiol. Mol. Biol. Rev. 1998, 62, 807-813.

11. Gill, S.S.; Hornung, J.M. Cytolytic activity of Bacillus thuringiensis proteins to insect and mammalian-cell lines. J. Invertebr. Pathol. 1987, 50, 16-25.

12. Mizuki, E.; Park, Y.S.; Saitoh, H.; Yamashita, S.; Akao, T.; Higuchi, K.; Ohba, M. Parasporin, a human leukemic cell-recognizing parasporal protein of Bacillus thuringiensis. Clin. Diagn. Lab. Immunol. 2000, 7, 625-634.

13. Okumura, S.; Ohba, M.; Mizuki, E.; Crickmore, N.; Côté, J.C.; Nagamatsu, Y.; Kitada, S.; Sakai, H.; Harata, K.; Shin, T. Parasporin nomenclature. 2010. Available online: http://parasporin.fitc.pref.fukuoka.jp/ (accessed on 3 September 2014). 
14. De Maagd, R.A.; Bravo, A.; Berry, C.; Crickmore, N.; Schnepf, H.E. Structure, diversity, and evolution of protein toxins from spore-forming entomopathogenic bacteria. Annu. Rev. Genet. 2003, 37, 409-433.

15. Estruch, J.J.; Warren, G.W.; Mullins, W.A.; Nye, G.J.; Craig, J.A.; Koziel, M.G. Vip3A, a novel Bacillus thuringiensis vegetative insecticidal protein with a wide spectrum of activities against lepidopteran insects. Proc. Natl. Acad. Sci. USA 1996, 93, 5389-5394.

16. Andrews, R.E.; Bibilos, M.M.; Bulla, L.A. Protease activation of the entomocidal protoxin of Bacillus thuringiensis subsp. kurstaki. Appl. Environ. Microbiol. 1985, 50, 737-742.

17. Zhang, X.; Candas, M.; Griko, N.B.; Rose-Young, L.; Bulla, L.A. Cytotoxicity of Bacillus thuringiensis Cry1Ab toxin depends on specific binding of the toxin to the cadherin receptor BT-R ${ }_{1}$ expressed in insect cells. Cell. Death. Differ. 2005, 12, 1407-1416.

18. Bravo, A.; Gómez, I.; Conde, J.; Munoz-Garay, C.; Sanchez, J.; Miranda, R.; Zhuang, M.; Gill, S.S.; Soberón, M. Oligomerization triggers binding of a Bacillus thuringiensis Cry1Ab pore-forming toxin to aminopeptidase $\mathrm{N}$ receptor leading to insertion into membrane microdomains. Biochim. Biophys. Acta 2004, 1667, 38-46.

19. Pardo-Lopez, L.; Munoz-Garay, C.; Porta, H.; Rodriguez-Almazan, C.; Soberon, M.; Bravo, A. Strategies to improve the insecticidal activity of Cry toxins from Bacillus thuringiensis. Peptides 2009, 30, 589-595.

20. Gonzalez, M.R.; Bischofberger, M.; Pernot, L.; van der Goot, F.G.; Freche, B. Bacterial pore-forming toxins: The (w)hole story? Cell. Mol. Life. Sci. 2008, 65, 493-507.

21. Feil, S.C.; Polekhina, G.; Gorman, M.A.; Parker, M.W. Proteins membrane binding and pore formation introduction. Adv. Exp. Med. Biol. 2010, 677, 1-13.

22. Geny, B.; Popoff, M.R. Bacterial protein toxins and lipids: Pore formation or toxin entry into cells. Biol. Cell. 2006, 98, 667-678.

23. Grochulski, P.; Masson, L.; Borisova, S.; Pusztaicarey, M.; Schwartz, J.L.; Brousseau, R.; Cygler, M. Bacillus thuringiensis CrylA(a) insecticidal toxin: Crystal structure and channel formation. J. Mol. Biol. 1995, 254, 447-464.

24. Derbyshire, D.J.; Ellar, D.J.; Li, J. Crystallization of the Bacillus thuringiensis toxin Cry1Ac and its complex with the receptor ligand N-acetyl-d-galactosamine. Acta Crystallogr. Sect. D: Biol. Crystallogr. 2001, 57, 1938-1944.

25. Morse, R.J.; Yamamoto, T.; Stroud, R.M. Structure of Cry2Aa suggests an unexpected receptor binding epitope. Structure 2001, 9, 409-417.

26. Li, J.D.; Carroll, J.; Ellar, D.J. Crystal structure of insecticidal $\delta$-endotoxin from Bacillus thuringiensis at $2.5 \AA$ resolution. Nature 1991, 353, 815-821.

27. Galitsky, N.; Cody, V.; Wojtczak, A.; Ghosh, D.; Luft, J.R.; Pangborn, W.; English, L. Structure of the insecticidal bacterial delta-endotoxin Cry3Bb1 of Bacillus thuringiensis. Acta Crystallogr. Sect. D: Biol. Crystallogr. 2001, 57, 1101-1109.

28. Boonserm, P.; Mo, M.; Angsuthanasombat, C.; Lescar, J. Structure of the functional form of the mosquito larvicidal Cry4Aa toxin from Bacillus thuringiensis at a 2.8-Angstrom resolution. J. Bacteriol. 2006, 188, 3391-3401.

29. Boonserm, P.; Davis, P.; Ellar, D.J.; Li, J. Crystal structure of the mosquito-larvicidal toxin Cry4Ba and its biological implications. J. Mol. Biol. 2005, 348, 363-382. 
30. Guo, S.Y.; Ye, S.; Liu, Y.F.; Wei, L.; Xue, J.; Wu, H.F.; Song, F.P.; Zhang, J.; Wu, X.A.; Huang, D.F.; et al. Crystal structure of Bacillus thuringiensis Cry8Ea1: An insecticidal toxin toxic to underground pests, the larvae of Holotrichia parallela. J. Struct. Biol. 2009, 168, 259-266.

31. Hui, F.; Scheib, U.; Hu, Y.; Sommer, R.J.; Aroian, R.V.; Ghosh, P. Structure and glycolipid binding properties of the nematicidal protein Cry5B. Biochemistry 2012, 51, 9911-9921.

32. de Maagd, R.A.; Bravo, A.; Crickmore, N. How Bacillus thuringiensis has evolved specific toxins to colonize the insect world. Trends Genet. 2001, 17, 193-199.

33. Gouet, P.; Robert, X.; Courcelle, E. ESPript/ENDscript: extracting and rendering sequence and 3D information from atomic structures of proteins. Nucl. Acids Res. 2003, 31, 3320-3323.

34. Soberón, M.; Pardo-Lopez, L.; Lopez, I.; Gómez, I.; Tabashnik, B.E.; Bravo, A. Engineering modified Bt toxins to counter insect resistance. Science 2007, 318, 1640-1642.

35. Porta, H.; Jimenez, G.; Cordoba, E.; Leon, P.; Soberón, M.; Bravo, A. Tobacco plants expressing the Cry1AbMod toxin suppress tolerance to CrylAb toxin of Manduca sexta cadherin-silenced larvae. Insect Biochem. Mol. Biol. 2011, 41, 513-519.

36. Vachon, V.; Prefontaine, G.; Rang, C.; Coux, F.; Juteau, M.; Schwartz, J.L.; Brousseau, R.; Frutos, R.; Laprade, R.; Masson, L. Helix 4 mutants of the Bacillus thuringiensis insecticidal toxin Cry1Aa display altered pore-forming abilities. Appl. Environ. Microbiol. 2004, 70, 6123-6130.

37. Tigue, N.J.; Jacoby, J.; Ellar, D.J. The $\alpha$-helix 4 residue, Asn135, is involved in the oligomerization of Cry1Ac1 and Cry1Ab5 Bacillus thuringiensis toxins. Appl. Environ. Microbiol. 2001, 67, $5715-5720$.

38. Kanintronkul, Y.; Sramala, I.; Katzenmeier, G.; Panyim, S.; Angsuthanasombat, C. Specific mutations within the $\alpha 4-\alpha 5$ loop of the Bacillus thuringiensis Cry4B toxin reveal a crucial role for Asn-166 and Tyr-170. Mol. Biotechnol. 2003, 24, 11-19.

39. Pornwiroon, W.; Katzenmeier, G.; Panyim, S.; Angsuthanasombat, C. Aromaticity of Tyr-202 in the $\alpha 4-\alpha 5$ loop is essential for toxicity of the Bacillus thuringiensis Cry4A toxin. J. Biochem. Mol. Biol. 2004, 37, 292-297.

40. Gazit, E.; la Rocca, P.; Sansom, M.S.P.; Shai, Y. The structure and organization within the membrane of the helices composing the pore-forming domain of Bacillus thuringiensis delta-endotoxin are consistent with an "umbrella-like" structure of the pore. Proc. Natl. Acad. Sci. USA 1998, 95, 12289-12294.

41. Gazit, E.; Shai, Y. The assembly and organization of the $\alpha 5$ and $\alpha 7$ helices from the pore-forming domain of Bacillus thuringiensis $\delta$-endotoxin: Relevance to a functional model. J. Biol. Chem. 1995, 270, 2571-2578.

42. Park, H.-W.; Federici, B. Effect of specific mutations in helix $\alpha 7$ of domain I on the stability and crystallization of Cry3A in Bacillus thuringiensis. Mol. Biotechnol. 2004, 27, 89-100.

43. Tiewsiri, K.; Fischer, W.B.; Angsuthanasombat, C. Lipid-induced conformation of helix 7 from the pore-forming domain of the Bacillus thuringiensis Cry4Ba toxin: Implications for toxicity mechanism. Arch. Biochem. Biophys. 2009, 482, 17-24.

44. Rajamohan, F.; Lee, M.K.; Dean, D.H. Bacillus thuringiensis insecticidal proteins: Molecular mode of action. Prog. Nucleic Acid. Res. Mol. Biol. 1998, 60, 1-27. 
45. Gómez, I.; Miranda-Rios, J.; Rudino-Pinera, E.; Oltean, D.I.; Gill, S.S.; Bravo, A.; Soberon, M. Hydropathic complementarity determines interaction of epitope ${ }^{869} \mathrm{HITDTNNK}^{876}$ in Manduca sexta Bt- $\mathrm{R}_{1}$ receptor with loop 2 of domain II of Bacillus thuringiensis Cry1A toxins. J. Biol. Chem. 2002, 277, 30137-30143.

46. Gómez, I.; Arenas, I.; Benitez, I.; Miranda-Rios, J.; Becerril, B.; Grande, R.; Almagro, J.C.; Bravo, A.; Soberón, M. Specific epitopes of domains II and III of Bacillus thuringiensis Cry1 Ab toxin involved in the sequential interaction with cadherin and aminopeptidase-N receptors in Manduca sexta. J. Biol. Chem. 2006, 281, 34032-34039.

47. Rajamohan, F.; Alzate, O.; Cotrill, J.A.; Curtiss, A.; Dean, D.H. Protein engineering of Bacillus thuringiensis $\delta$-endotoxin: Mutations at domain II of CryIAb enhance receptor affinity and toxicity toward gypsy moth larvae. Proc. Natl. Acad. Sci. USA 1996, 93, 14338-14343.

48. Rajamohan, F.; Hussain, S.R.A.; Cotrill, J.A.; Gould, F.; Dean, D.H. Mutations at domain II, loop 3, of Bacillus thuringiensis CryIAa and CryIAb $\delta$-endotoxins suggest loop 3 is involved in initial binding to lepidopteran midguts. J. Biol. Chem. 1996, 271, 25220-25226.

49. Lee, M.K.; Rajamohan, F.; Jenkins, J.L.; Curtiss, A.S.; Dean, D.H. Role of two arginine residues in domain II, loop 2 of Cry1Ab and Cry1Ac Bacillus thuringiensis $\delta$-endotoxin in toxicity and binding to Manduca sexta and Lymantria dispar aminopeptidase N. Mol Microbiol 2000, 38, 289-298.

50. Arenas, I.; Bravo, A.; Soberón, M.; Gómez, I. Role of alkaline phosphatase from Manduca sexta in the mechanism of action of Bacillus thuringiensis Cry1 Ab toxin. J. Biol. Chem. 2010, 285, 12497-12503.

51. Gómez, I.; Dean, D.H.; Bravo, A.; Soberon, M. Molecular basis for Bacillus thuringiensis $\mathrm{Cry} 1 \mathrm{Ab}$ toxin specificity: Two structural determinants in the Manduca sexta Bt- $\mathrm{R}_{1}$ receptor interact with loops $\alpha 8$ and 2 in domain II of Cy1Ab toxin. Biochemistry 2003, 42, 10482-10489.

52. Atsumi, S.; Inoue, Y.; Ishizaka, T.; Mizuno, E.; Yoshizawa, Y.; Kitami, M.; Sato, R. Location of the Bombyx mori $175 \mathrm{kDa}$ cadherin-like protein-binding site on Bacillus thuringiensis Cry1Aa toxin. FEBS J. 2008, 275, 4913-4926.

53. Xie, R.Y.; Zhuang, M.B.; Ross, L.S.; Gomez, I.; Oltean, D.I.; Bravo, A.; Soberon, M.; Gill, S.S. Single amino acid mutations in the cadherin receptor from Heliothis virescens affect its toxin binding ability to Cry1A toxins. J. Biol. Chem. 2005, 280, 8416-8425.

54. Pacheco, S.; Gomez, I.; Arenas, I.; Saab-Rincon, G.; Rodriguez-Almazan, C.; Gill, S.S.; Bravo, A.; Soberon, M. Domain II loop 3 of Bacillus thuringiensis Cry1Ab toxin is involved in a "ping pong" binding mechanism with Manduca sexta aminopeptidase-N and cadherin receptors. J. Biol. Chem. 2009, 284, 32750-32757.

55. Chen, J.; Brown, M.R.; Hua, G.; Adang, M.J. Comparison of the localization of Bacillus thuringiensis Cry1A $\delta$-endotoxins and their binding proteins in larval midgut of tobacco hornworm, Manduca sexta. Cell. Tissue. Res. 2005, 321, 123-129.

56. Aronson, A.I.; Wu, D.; Zhang, C.L. Mutagenesis of specificity and toxicity regions of a Bacillus thuringiensis protoxin gene. J. Bacteriol. 1995, 177, 4059-4065.

57. De Maagd, R.A.; Kwa, M.S.G.; van der Klei, H.; Yamatoto, T.; Schipper, B.; Vlak, J.M.; Stiekema, W.; Bosch, D. Domain III substitution in Bacillus thuringiensis $\delta$-endotoxin CryIA(b) results in superior toxicity for Spodoptera exigua and altered membrane protein recognition. Appl. Environ. Microbiol. 1996, 62, 1537-1543. 
58. Lee, M.K.; Young, B.A.; Dean, D.H. Domain III exchanges of Bacillus thuringiensis CryIA toxins affect binding to different gypsy moth midgut receptors. Biochem. Biophys. Res. Commun. 1995, 216, 306-312.

59. Masson, L.; Lun, Y.J.; Mazza, A.; Brousseau, R.; Adang, M.J. The CryIA(c) receptor purified from Manduca sexta displays mltiple specificities. J. Biol. Chem. 1995, 270, 20309-20315.

60. Burton, S.L.; Ellar, D.J.; Li, J.; Derbyshire, D.J. N-acetylgalactosamine on the putative insect receptor aminopeptidase $\mathrm{N}$ is recognised by a site on the domain III lectin-like fold of a Bacillus thuringiensis insecticidal toxin. J. Mol. Biol. 1999, 287, 1011-1022.

61. Shan, S.; Zhang, Y.; Ding, X.; Hu, S.; Sun, Y.; Yu, Z.; Liu, S.; Zhu, Z.; Xia, L. A Cry1Ac toxin variant generated by directed evolution has enhanced toxicity against lepidopteran insects. Curr. Microbiol. 2011, 62, 358-365.

62. Liu, Y.; Wang, Q.; Wang, F.; Ding, X.; Xia, L. Residue 544 in Domain III of the Bacillus thuringiensis Cry1Ac toxin is involved in protein structure stability. Protein J. 2010, 29, 440-444.

63. Tabashnik, B.E.; Liu, Y.-B.; de Maagd, R.A.; Dennehy, T.J. Cross-resistance of pink bollworm (Pectinophora gossypiella) to Bacillus thuringiensis toxins. Appl. Environ. Microbiol. 2000, 66, 4582-4584.

64. Akiba, T.; Ichimatsu, T.; Katayama, H.; Akao, T.; Nakamura, O.; Mizuki, E.; Ohba, M.; Harata, K. Structure of parasporin-1, a novel bacterial cytotoxin against human cancer cells. Acta Crystallogr. Sect. A 2005, A61, C250.

65. Katayama, H.; Kusaka, Y.; Yokota, H.; Akao, T.; Kojima, M.; Nakamura, O.; Mekada, E.; Mizuki, E. Parasporin-1, a novel cytotoxic protein from Bacillus thuringiensis, induces $\mathrm{Ca}^{2+}$ influx and a sustained elevation of the cytoplasmic $\mathrm{Ca}^{2+}$ concentration in toxin-sensitive cells. J. Biol. Chem. 2007, 282, 7742-7752.

66. Yamashita, S.; Katayama, H.; Saitoh, H.; Akao, T.; Park, Y.S.; Mizuki, E.; Ohba, M.; Ito, A. Typical three-domain Cry proteins of Bacillus thuringiensis strain A1462 exhibit cytocidal activity on limited human cancer cells. J. Biochem. 2005, 138, 663-672.

67. Vidisha, K. Investigation of Parasporins, the Cytotoxic Proteins from the Bacterium Bacillus thuringiensis. Ph.D. Thesis, University of Sussex, Brighton, UK, 2013.

68. Nagamatsu, Y.; Okamura, S.; Saitou, H.; Akao, T.; Mizuki, E. Three Cry toxins in two types from Bacillus thuringiensis strain M019 preferentially kill human hepatocyte cancer and uterus cervix cancer cells. Biosci. Biotechnol. Biochem. 2010, 74, 494-498.

69. Iacovache, I.; van der Goot, F.G.; Pernot, L. Pore formation: An ancient yet complex form of attack. Biochim. Biophys. Acta 2008, 1778, 1611-1623.

70. Parker, M.W.; Postma, J.P.M.; Pattus, F.; Tucker, A.D.; Tsernoglou, D. Refined structure of the pore-forming domain of colicin A at $2.4 \AA$ resolution. J. Biol. Chem. 1992, 224, 639-657.

71. Padmavathi, P.V.L.; Steinhoff, H.J. Conformation of the closed channel state of colicin A in proteoliposomes: An umbrella model. J. Mol. Biol. 2008, 378, 204-214.

72. Lakey, J.H.; van der Goot, F.G.; Pattus, F. All in the family: The toxic activity of pore-forming colicins. Toxicology 1994, 87, 85-108.

73. Braun, V.; Pils1, H.; Gross, P. Colicins: Structures, modes of action, transfer through membranes, and evolution. Arch. Microbiol. 1994, 161, 199-206. 
74. Kanagawa, M.; Satoh, T.; Ikeda, A.; Nakano, Y.; Yagi, H.; Kato, K.; Kojima-Aikawa, K.; Yamaguchi, Y. Crystal structures of human secretory proteins ZG16p and ZG16b reveal a Jacalin-related beta-prism fold. Biochem. Biophys. Res. Commun. 2011, 404, 201-205.

75. Holm, L.; Rosenstrom, R. Dali server: Conservation mapping in 3D. Nucleic Acids Res. 2010, 38, W545-W549.

76. Kumazawa-Inoue, K.; Mimura, T.; Hosokawa-Tamiya, S.; Nakano, Y.; Dohmae, N.; Kinoshita-Toyoda, A.; Toyoda, H.; Kojima-Aikawa, K. ZG16p, an animal homolog of beta-prism fold plant lectins, interacts with heparan sulfate proteoglycans in pancreatic zymogen granules. Glycobiology 2012, 22, 258-266.

77. Kleene, R.; Dartsch, H.; Kern, H.F. The secretory lectin ZG16p mediates sorting of enzyme proteins to the zymogen granule membrane in pancreatic acinar cells. Eur. J. Cell. Biol. 1999, 18, 79-90.

78. Schmidt, K.; Schrader, M.; Kern, H.F.; Kleene, R. Regulated apical secretion of zymogens in rat pancreas involvement of the glycosylophophatidylinositol-anchored glycoprotein GP-2, the lectin ZG16p, and cholesterol-glycophingolipid-enriched microdomains. J. Biol. Chem. 2001, 276, 14314-14323.

79. Sankaranarayanan, R.; Sekar, K.; Banerjee, R.; Sharma, V.; Surolia, A.; Vijayan, M. A novel mode of carbohydrate recognition in jacalin, a Moraceae plant lectin with a $\beta$-prism fold. Nat. Struct. Mol. Biol. 1996, 3, 596-603.

80. Michel, G.; Barbeyron, T.; Kloareg, B.; Czjzek, M. The family 6 carbohydrate-binding modules have coevolved with their appended catalytic modules toward similar substrate specificity. Glycobiology 2009, 19, 615-623.

81. Guillén, D.; Sánchez, S.; Rodríguez-Sanoja, R. Carbohydrate-binding domains: Multiplicity of biological roles. Appl. Microbiol. Biotechnol 2010, 85, 1241-1249.

82. Pires, V.M.R.; Henshaw, J.L.; Prates, J.A.M.; Bolam, D.N.; Ferreira, L.M.A.; Fontes, C.M.G.A.; Henrissat, B.; Planas, A.; Gilbert, H.J.; et al. The crystal structure of the family 6 carbohydrate binding module from Cellvibrio mixtus endoglucanase 5A in complex with oligosaccharides reveals two distinct binding sites with different ligand specificities. J. Biol. Chem. 2004, 279, 21560-21568.

83. Bravo, A.; Likitvivatanavong, S.; Gill, S.S.; Soberón, M. Bacillus thuringiensis: A story of a successful bioinsecticide. Insect Biochem. Mol. Biol. 2011, 41, 423-431.

84. Gómez, I.; Sanchez, J.; Miranda, R.; Bravo, A.; Soberon, M. Cadherin-like receptor binding facilitates proteolytic cleavage of helix $\alpha 1$ in domain $I$ and oligomer pre-pore formation of Bacillus thuringiensis Cry1 Ab toxin. FEBS Lett. 2002, 513, 242-246.

85. Soberón, M.; Gill, S.S.; Bravo, A. Signaling versus punching hole: How do Bacillus thuringiensis toxins kill insect midgut cells? Cell. Mol. Life Sci. 2009, 66, 1337-1349.

86. Greig, S.L.; Radjainia, M.; Mitra, A.K. Oligomeric structure of Colicin Ia channel in lipid bilayer membranes. J. Biol. Chem. 2009, 284, 16126-16134.

87. Groulx, N.; McGuire, H.; Laprade, R.; Schwartz, J.-L.; Blunck, R. Single molecule fluorescence study of the Bacillus thuringiensis toxin Cry1Aa reveals tetramerization. J. Biol. Chem. 2011, 286, 42274-42282. 
88. Pigott, C.R.; Ellar, D.J. Role of receptors in Bacillus thuringiensis crystal toxin activity. Microbiol. Mol. Biol. Rev. 2007, 71, 255-281.

89. Zhang, X.B.; Candas, M.; Griko, N.B.; Taussig, R.; Bulla, L.A. A mechanism of cell death involving an adenylyl cyclase/PKA signaling pathway is induced by the Cry1 Ab toxin of Bacillus thuringiensis. Proc. Natl. Acad. Sci. USA 2006, 103, 9897-9902.

90. Vachon, V.; Laprade, R.; Schwartz, J.L. Current models of the mode of action of Bacillus thuringiensis insecticidal crystal proteins: A critical review. J. Invertebr. Pathol. 2012, 111, 1-12.

91. Schwartz, J.L.; Garneau, L.; Masson, L.; Brousseau, R. Early response of cultured lepidopteran cells to exposure to $\delta$-endotoxin from Bacillus thuringiensis: Involvement of calcium and anionic channels. Biochim. Biophys. Acta. 1991, 1065, 250-260.

92. Jurat-Fuentes, J.L.; Adang, M.J. Cry toxin mode of action in susceptible and resistant Heliothis virescens larvae. J. Invertebr. Pathol. 2006, 92, 166-171.

93. Thomas, W.E.; Ellar, D.J. Bacillus thuringiensis var. israelensis crystal $\delta$-endotoxin: Effects on insect and mammalian cells in vitro and in vivo. J. Cell. Sci. 1983, 60, 181-197.

94. Koni, P.A.; Ellar, D.J. Biochemical characterization of Bacillus thuringiensis cytolytic $\delta$-endotoxins. Microbiology 1994, 140, 1869-1880.

95. Berry, C.; O’Neil, S.; Ben-Dov, E.; Jones, A.F.; Murphy, L.; Quail, M.A.; Holden, M.T.G.; Harris, D.; Zaritsky, A.; Parkhill, J. Complete sequence and organization of pBtoxis, the toxin-coding plasmid of Bacillus thuringiensis subsp. israelensis. Appl. Environ. Microbiol. 2002, 68, 5082-5095.

96. Cohen, S.; Albeck, S.; Ben-Dov, E.; Cahan, R.; Firer, M.; Zaritsky, A.; Dym, O. Cyt1Aa toxin: Crystal structure reveals implications for its membrane-perforating function. J. Mol. Biol. 2011, $413,804-814$.

97. Cohen, S.; Dym, O.; Albeck, S.; Ben-Dov, E.; Cahan, R.; Firer, M.; Zaritsky, A. High-resolution crystal structure of activated Cyt2Ba monomer from Bacillus thuringiensis subsp. israelensis. J. Mol. Biol. 2008, 380, 820-827.

98. Li, J.; Koni, P.A.; Ellar, D.J. Structure of the mosquitocidal $\delta$-endotoxin CytB from Bacillus thuringiensis sp. kyushuensis and implications for membrane pore formation. J. Mol. Biol. 1996, 257, 129-152.

99. Butko, P. Cytolytic toxin Cyt1A and tts mechanism of membrane damage: Data and hypotheses. Appl. Environ. Microbiol. 2003, 69, 2415-2422.

100. Lin, S.C.; Lo, Y.C.; Lin, J.Y.; Liaw, Y.C. Crystal structures and electron micrographs of fungal volvatoxin A2. J. Mol. Biol. 2004, 343, 477-491.

101. Lin, S.C.; Lin, J.Y.; Liaw, Y.C. Crystallization and preliminary X-ray analysis of volvatoxin A2 from Volvariella volvacea. Proteins 1996, 24, 141-142.

102. Lin, J.F.; Jeng, T.W.; Chen, C.C.; Shi, G.Y.; Tung, T.C. Isolation of a new cardiotoxic protein from the edible mushroom, Volvariella volvacea. Nature 1973, 246, 524-525.

103. Wu, P.T.; Lin, S.C.; Hsu, C.I.; Liaw, Y.C.; Lin, J.Y. Inhibitory effects of nontoxic protein volvatoxin A1 on pore-forming cardiotoxic protein volvatoxin A2 by interaction with amphipathic alpha-helix. FEBS J. 2006, 273, 3160-3171.

104. Weng, Y.P.; Lin, Y.P.; Hsu, C.I.; Lin, J.Y. Functional domains of a pore-forming cardiotoxic protein, volvatoxin A2. J. Biol. Chem. 2004, 279, 6805-6814. 
105. Rodriguez-Almazan, C.; de Escudero, I.R.; Canton, P.E.; Munoz-Garay, C.; Perez, C.; Gill, S.S.; Soberón, M.; Bravo, A. The amino- and carboxyl-terminal fragments of the Bacillus thuringensis Cyt1Aa toxin have differential roles in toxin oligomerization and pore formation. Biochemistry 2011, 50, 388-396.

106. Du, J.P.; Knowles, B.H.; Li, J.; Ellar, D.J. Biochemical characterization of Bacillus thuringiensis cytolytic toxins in association with a phospholipid bilayer. Biochem. J. 1999, 338, 185-193.

107. Gazit, E.; Burshtein, N.; Ellar, D.J.; Sawyer, T.; Shai, Y. Bacillus thuringiensis cytolytic toxin associates specifically with its synthetic helices $\mathrm{A}$ and $\mathrm{C}$ in the membrane bound state. Implications for the assembly of oligomeric transmembrane pores. Biochemistry 1997, 36, $15546-15554$.

108. Promdonkoy, B.; Rungrod, A.; Promdonkoy, P.; Pathaichindachote, W.; Krittanai, C.; Panyim, S. Amino acid substitutions in $\alpha \mathrm{A}$ and $\alpha \mathrm{C}$ of Cyt2Aa2 alter hemolytic activity and mosquito-larvicidal specificity. J. Biotech. 2008, 133, 287-293.

109. Porter, A.G.; Davidson, E.W.; Liu, J.W. Mosquitocidal toxins of Bacilli and their genetic manipulation for effective bological control of mosquitos. Microbiol. Rev. 1993, 57, 838-861.

110. Pérez, C.; Fernandez, L.E.; Sun, J.G.; Folch, J.L.; Gill, S.S.; Soberon, M.; Bravo, A. Bacillus thuringiensis subsp. israelensis Cyt1Aa synergizes Cry11Aa toxin by functioning as a membrane-bound receptor. Proc. Natl. Acad. Sci. USA 2005, 102, 18303-18308.

111. Cantón, P.E.; Reyes, E.Z.; de Escudero, I.R.; Bravo, A.; Soberón, M. Binding of Bacillus thuringiensis subsp. israelensis Cry4Ba to Cyt1Aa has an important role in synergism. Peptides 2011, 32, 595-600.

112. Wirth, M.C.; Georghiou, G.P.; Federici, B.A. CytA enables CryIV endotoxins of Bacillus thuringiensis to overcome high levels of CryIV resistance in the mosquito, Culex quinquefasciatus. Proc. Natl. Acad. Sci. USA 1997, 94, 10536-10540.

113. Pérez, C.; Munoz-Garay, C.; Portugal, L.C.; Sanchez, J.; Gill, S.S.; Soberon, M.; Bravo, A. Bacillus thuringiensis ssp. israelensis Cyt1Aa enhances activity of Cry11Aa toxin by facilitating the formation of a pre-pore oligomeric structure. Cell. Microbiol. 2007, 9, 2931-2937.

114. Hua, G.; Jurat-Fuentes, J.L.; Adang, M.J. Fluorescent-based assays establish Manduca sexta Bt- $\mathrm{R}_{1 \mathrm{a}}$ cadherin as a receptor for multiple Bacillus thuringiensis Cry1A toxins in Drosophila S2 cells. Insect Biochem. Mol. Biol. 2004, 34, 193-202.

115. Bravo, A.; Soberón, M. How to cope with insect resistance to Bt toxins? Trends Biotechnol. 2008, 26, 573-579.

116. Bravo, A.; Gill, S.S.; Soberón, M. Mode of action of Bacillus thuringiensis Cry and Cyt toxins and their potential for insect control. Toxicon 2007, 49, 423-435.

117. Mizuki, E.; Ohba, M.; Akao, T.; Yamashita, S.; Saitoh, H.; Park, Y.S. Unique activity associated with non-insecticidal Bacillus thuringiensis parasporal inclusions: In vitro cell-killing action on human cancer cells. J. Appl. Microbiol 1999, 86, 477-486.

118. Ohba, M.; Mizuki, E.; Uemori, A. Parasporin, a newanticancer protein group from Bacillus thuringiensis. Anticancer Res. 2009, 29, 427-433.

119. Kitada, S.; Abe, Y.; Shimada, H.; Kusaka, Y.; Matsuo, Y.; Katayama, H.; Okumura, S.; Akao, T.; Mizuki, E.; Kuge, O.; et al. Cytocidal actions of parasporin-2, an anti-tumor crystal toxin from Bacillus thuringiensis. J. Biol. Chem. 2006, 281, 26350-26360. 
120. Katayama, H.; Yokota, H.; Akao, T.; Nakamura, O.; Ohba, M.; Mekada, E.; Mizuki, E. Parasporin-1, a novel cytotoxic protein to human cells from non-insecticidal parasporal inclusions of Bacillus thuringiensis. J. Biochem. 2005, 137, 17-25.

121. Katayama, H.; Kusaka, Y.; Mizuk, E. Parasproin-1 Receptor and Use Thereof. U.S. Patent 20110038880, filed 30 March 2009, and issued 17 February 2011.

122. Liang, X.H.; Jackson, S.; Seaman, M.; Brown, K.; Kempkes, B.; Hibshoosh, H.; Levine, B. Induction of autophagy and inhibition of tumorigenesis by beclin 1. Nature 1999, 402, 672-676.

123. Wirawan, E.; Lippens, S.; Vanden Berghe, T.; Romagnoli, A.; Fimia, G.M.; Piacentini, M.; Vandenabeele, P. Beclin1: A role in membrane dynamics and beyond. Autophagy 2012, 8, 6-17.

124. Kim, H.S.; Yamashita, S.; Akao, T.; Saitoh, H.; Higuchi, K.; Park, Y.S.; Mizuki, E.; Ohba, M. In vitro cytotoxicity of non-Cyt inclusion proteins of a Bacillus thuringiensis isolate against human cells, including cancer cells. J. Appl. Microbiol. 2000, 89, 16-23.

125. Ito, A.; Sasaguri, Y.; Kitada, S.; Kusaka, Y.; Kuwano, K.; Masutomi, K.; Mizuki, E.; Akao, T.; Ohba, M. A Bacillus thuringiensis crystal protein with selective cytocidal action to human cells. J. Biol. Chem. 2004, 279, 21282-21286.

126. Akiba, T.; Abe, Y.; Kitada, S.; Kusaka, Y.; Ito, A.; Ichimatsu, T.; Katayama, H.; Akao, T.; Higuchi, K.; Mizuki, E.; et al. Crystal structure of the parasporin-2 Bacillus thuringiensis toxin that recognizes cancer cells. J. Mol. Biol. 2009, 386, 121-133.

127. Abe, Y.; Shimada, H.; Kitada, S. Raft-targeting and oligomerization of parasporin-2, a Bacillus thuringiensis crystal protein with anti-tumour activity. J. Biochem. 2008, 143, 269-275.

128. Legler, D.F.; Doucey, M.A.; Schneider, P.; Chapatte, L.; Bender, F.C.; Bron, C. Differential insertion of GPI-anchored GFPs into lipid rafts of live cells. FASEB J. 2004, 18, 73-75.

129. Lingwood, D.; Kaiser, H.J.; Levental, I.; Simons, K. Lipid rafts as functional heterogeneity in cell membranes. Biochem. Soc. Trans. 2009, 37, 955-960.

130. Kitada, S.; Abe, Y.; Maeda, T.; Shimada, H. Parasporin-2 requires GPI-anchored proteins for the efficient cytocidal action to human hepatoma cells. Toxicology 2009, 264, 80-88.

131. Yamashita, S.; Akao, T.; Mizuki, E.; Saitoh, H.; Higuchi, K.; Park, Y.S.; Kim, H.S.; Ohba, M. Characterization of the anti-cancer-cell parasporal proteins of a Bacillus thuringiensis isolate. Can. J. Microbiol. 2000, 46, 913-919.

132. Lee, D.W.; Akao, T.; Yamashita, S.; Katayama, H.; Maeda, M.; Saitoh, H.; Mizuki, E.; Ohba, M. Noninsecticidal parasporal proteins of a Bacillus thuringiensis serovar shandongiensis isolate exhibit a preferential cytotoxicity against human leukemic T cells. Biochem. Biophys. Res. Commun. 2000, 272, 218-223.

133. Lee, D.W.; Katayama, H.; Akao, T.; Maeda, M.; Tanaka, R.; Yamashita, S.; Saitoh, H.; Mizuki, E.; Ohba, M. A $28 \mathrm{kDa}$ protein of the Bacillus thuringiensis serovar shandongiensis isolate 89-T-34-22 induces a human leukemic cell-specific cytotoxicity. Biochim. Biophys. Acta 2001, 1547, 57-63.

134. Okumura, S.; Akao, T.; Higuchi, K.; Saitoh, H.; Mizuki, E.; Ohba, M.; Inouye, K. Bacillus thuringiensis serovar shandongiensis strain 89-T-34-22 produces multiple cytotoxic proteins with similar molecular masses against human cancer cells. Lett. Appl. Microbiol. 2004, 39, 89-92. 
135. Okumura, S.; Saitoh, H.; Ishikawa, T.; Wasano, N.; Yamashita, S.; Kusumoto, K.; Akao, T.; Mizuki, E.; Ohba, M.; Inouye, K. Identification of a novel cytotoxic protein, Cry45Aa, from Bacillus thuringiensis A1470 and its selective cytotoxic activity against various mammalian cell lines. J. Agric. Food. Chem. 2005, 53, 6313-6318.

136. Saitoh, H.; Okumura, S.; Ishikawa, T.; Akao, T.; Mizuki, E.; Ohba, M. Investigation of a novel Bacillus thuringiensis gene encoding a parasporal protein, parasporin-4, that preferentially kills human leukemic T cells. Biosci. Biotechnol. Biochem. 2006, 70, 2935-2941.

137. Okumura, S.; Saitoh, H.; Ishikawa, T.; Mizuki, E.; Inouye, K. Identification and characterization of a novel cytotoxic protein, parasporin-4, produced by Bacillus thuringiensis A1470 strain. Biotechnol. Annu. Rev. 2008, 14, 225-252.

138. Okumura, S.; Saitoh, H.; Ishikawa, T.; Inouye, K.; Mizuki, E. Mode of action of parasporin-4, a cytocidal protein from Bacillus thuringiensis. Biochim. Biophys. Acta. 2011, 1808, 1476-1482.

139. Parker, M.W.; Buckley, J.T.; Postma, J.P.M.; Tucker, A.D.; Leonard, K.; Pattus, F.; Tsernoglou, D. Structure of the Aeromonas toxin proaerolysin in its water-soluble and membrane-channel states. Nature 1994, 367, 292-295.

140. Szczesny, P.; Iacovache, I.; Muszewska, A.; Ginalski, K.; van der Goot, F.G.; Grynberg, M. Extending the aerolysin family: From bacteria to vertebrates. PLoS One 2011, 6, e20349.

141. Knapp, O.; Stiles, B.G.; Popoff, M.R. The aerolysin-like toxin family of cytolytic, pore-forming toxins. Open Toxicol. J. 2010, 3, 53-68.

142. Briggs, D.C.; Naylor, C.E.; Smedley, J.G.; Lukoyanova, N.; Robertson, S.; Moss, D.S.; McClane, B.A.; Basak, A.K. Structure of the food-poisoning Clostridium perfringens enterotoxin reveals similarity to the aerolysin-like pore-forming toxins. J. Mol. Biol. 2011, 413, 138-149.

143. Akiba, T.; Higuchi, K.; Mizuki, E.; Ekino, K.; Shin, T.; Ohba, M.; Kanai, R.; Harata, K. Nontoxic crystal protein from Bacillus thuringiensis demonstrates a remarkable structural similarity to pore-forming toxins. Proteins: Struct. Funct. Bioinf. 2006, 63, 243-248.

144. Akiba, T.; Abe, Y.; Kitada, S.; Kusaka, Y.; Ito, A.; Ichimatsu, T.; Katayama, H.; Akao, T.; Higuchi, K.; Mizuki, E.; et al. Crystallization of parasporin-2, a Bacillus thuringiensis crystal protein with selective cytocidal activity against human cells. Acta Crystallogr. Sect. D: Biol. Crystallogr. 2004, 60, 2355-2357.

145. Guex, N.; Peitsch, M.C.; Schwede, T. Automated comparative protein structure modeling with SWISS-MODEL and Swiss-PdbViewer: A historical perspective. Electrophoresis 2009, 30, 162-173.

146. Cole, A.R.; Gibert, M.; Popoff, M.; Moss, D.S.; Titball, R.W.; Basak, A.K. Clostridium perfringens epsilon-toxin shows structural similarity to the pore-forming toxin aerolysin. Nat. Struct. Mol. Biol. 2004, 11, 797-798.

147. Payne, C.M.; Bomble, Y.J.; Taylor, C.B.; McCabe, C.; Himmel, M.E.; Crowley, M.F.; Beckham, G.T. Multiple functions of aromatic-carbohydrate interactions in a processive cellulase examined with molecular simulation. J. Biol. Chem. 2011, 286, 41028-42035.

148. Schwartz, R.; Istrail, S.; King, J. Frequencies of amino acid strings in globular protein sequences indicate suppression of blocks of consecutive hydrophobic residues. Protein Sci. 2001, 10, 1023-1031. 
149. Melton, J.A.; Parker, M.W.; Rossjohn, J.; Buckley, J.T.; Tweten, R.K. The identification and structure of the membrane-spanning domain of the Clostridium septicum $\alpha$-toxin. J. Biol. Chem. 2004, 279, 14315-14322.

150. Knapp, O.; Maier, E.; Benz, R.; Geny, B.; Popoff, M.R. Identification of the channel-forming domain of Clostridium perfringens epsilon-toxin (ETX). Biochim. Biophys. Acta-Biomembr. 2009, 1788, 2584-2593.

151. Mancheño, J.M.; Tateno, H.; Goldstein, I.J.; Martínez-Ripoll, M.; Hermoso, J.A. Structural analysis of the Laetiporus sulphureus hemolytic pore-forming lectin in complex with sugars. J. Biol. Chem. 2005, 280, 17251-17259.

152. Kitadokoro, K.; Nishimura, K.; Kamitani, S.; Fukui-Miyazaki, A.; Toshima, H.; Abe, H.; Kamata, Y.; Sugita-Konishi, Y.; Yamamoto, S.; Karatani, H.; et al. Crystal structure of Clostridium perfringens enterotoxin dsplays features of $\beta$-pore-forming toxins. J. Biol. Chem. 2011, 286, 19549-19555.

153. Hong, Y.J.; Ohishi, K.; Inoue, N.; Kang, J.Y.; Shime, H.; Horiguchi, Y.; van der Goot, F.G.; Sugimoto, N.; Kinoshita, T. Requirement of N-glycan on GPI-anchored proteins for efficient binding of aerolysin but not Clostridium septicum alpha-toxin. EMBO J. 2002, 21, 5047-5056.

154. Simpson, P.J.; Xie, H.F.; Bolam, D.N.; Gilbert, H.J.; Williamson, M.P. The structural basis for the ligand specificity of family 2 carbohydrate-binding modules. J. Biol. Chem. 2000, 275, 41137-41142.

155. Hashimoto, H. Recent structural studies of carbohydrate-binding modules. Cell. Mol. Life. Sci. 2006, 63, 2954-2967.

156. Mancheño, J.M.; Tateno, H.; Sher, D.; Goldstein, I.J. Laetiporus sulphureus lectin and aerolysin protein family. In Proteins Membrane Binding and Pore Formation; Springer New York: New York, NY, USA, 2010; Volume 677, pp. 67-80.

157. Rossjohn, J.; Feil, S.C.; McKinstry, W.J.; Tsernoglou, D.; van der Goot, G.; Buckley, J.T.; Parker, M.W. Aerolysin-a paradigm for membrane insertion of beta-sheet protein toxins? J. Struct. Biol. 1998, 121, 92-100.

158. Vandergoot, F.G.; Hardie, K.R.; Parker, M.W.; Buckley, J.T. The C-terminal peptide produced upon proteolytic activation of the cytolytic toxin aerolysin is not involved in channel formation. J. Biol. Chem. 1994, 269, 30496-30501.

159. Degiacomi, M.T.; Lacovache, I.; Pernot, L.; Chami, M.; Kudryashev, M.; Stahlberg, H.; van der Goot, F.G.; dal Peraro, M. Molecular assembly of the aerolysin pore reveals a swirling membrane-insertion mechanism. Nat. Chem. Biol. 2013, 9, 623-629.

160. Wilmsen, H.U.; Leonard, K.R.; Tichelaar, W.; Buckley, J.T.; Pattus, F. The aerolysin membrane channel is formed by heptamerization of the monomer. EMBO J. 1992, 11, 2457-2463.

161. Tsitrin, Y.; Morton, C.J.; El Bez, C.; Paumard, P.; Velluz, M.C.; Adrian, M.; Dubochet, J.; Parker, M.W.; Lanzavecchia, S.; van der Goot, F.G. Conversion of a transmembrane to a watersoluble protein complex by a single point mutation. Nat. Struct. Biol. 2002, 9, 729-733.

162. Iacovache, I.; Paumard, P.; Scheib, H.; Lesieur, C.; Sakai, N.; Matile, S.; Parker, M.W.; van der Goot, F.G. A rivet model for channel formation by aerolysin-like pore-forming toxins. EMBO J. 2006, 25, 457-466.

163. Whisstock, J.C.; Dunstone, M.A. Torqueing about pores. Nat. Chem. Biol. 2013, 9, 605-606. 
164. Yu, Z.; Luo, H.; Xiong, J.; Zhou, Q.; Xia, L.; Sun, M.; Li, L. Bacillus thuringiensis Cry6A exhibits nematicidal activity to Caenorhabditis elegans bre mutants and synergistic activity with Cry5B to C. elegans. Lett. Appl. Microbiol. 2014, 58, 511-519.

165. Naimov, S.; Boncheva, R.; Karlova, R.; Dukiandjiev, S.; Minkov, I.; de Maagd, R.A. Solubilization, activation, and insecticidal activity of Bacillus thuringiensis serovar thompsoni HD542 crystal proteins. Appl. Environ. Microbiol. 2008, 74, 7145-7151.

166. Masson, L.; Schwab, G.; Mazza, A.; Brousseau, R.; Potvin, L.; Schwartz, J.L. A novel Bacillus thuringiensis (PS149B1) containing a Cry34Abl/Cry35Abl binary toxin specific for the western corn rootworm Diabrotica virgifera virgifera LeConte forms ion channels in lipid membranes. Biochemistry 2004, 43, 12349-12357.

(C) 2014 by the authors; licensee MDPI, Basel, Switzerland. This article is an open access article distributed under the terms and conditions of the Creative Commons Attribution license (http://creativecommons.org/licenses/by/3.0/). 